\title{
Dihydromyricetin As a Novel Anti-Alcohol Intoxication Medication
}

\author{
Yi Shen, ${ }^{1}$ A. Kerstin Lindemeyer, ${ }^{1}$ Claudia Gonzalez, ${ }^{1}$ Xuesi M. Shao, ${ }^{2}$ Igor Spigelman, ${ }^{3}$ Richard W. Olsen, ${ }^{1}$ \\ and Jing Liang ${ }^{1}$ \\ Departments of ${ }^{1}$ Molecular and Medical Pharmacology and ${ }^{2}$ Neurobiology, David Geffen School of Medicine, and ${ }^{3}$ Division of Oral Biology and Medicine, \\ School of Dentistry, University of California, Los Angeles, California 90095
}

\begin{abstract}
Alcohol use disorders (AUDs) constitute the most common form of substance abuse. The development of AUDs involves repeated alcohol use leading to tolerance, alcohol withdrawal syndrome, and physical and psychological dependence, with loss of ability to control excessive drinking. Currently there is no effective therapeutic agent for AUDs without major side effects. Dihydromyricetin (DHM; 1 $\mathrm{mg} / \mathrm{kg}$, i.p. injection), a flavonoid component of herbal medicines, counteracted acute alcohol (EtOH) intoxication, and also withdrawal signs in rats including tolerance, increased anxiety, and seizure susceptibility; DHM greatly reduced EtOH consumption in an intermittent voluntary EtOH intake paradigm in rats. $\mathrm{GABA}_{\mathrm{A}}$ receptors $\left(\mathrm{GABA}_{\mathrm{A}} \mathrm{Rs}\right)$ are major targets of acute and chronic EtOH actions on the brain. At the cellular levels, DHM $(1 \mu \mathrm{M})$ antagonized both acute EtOH-induced potentiation of $\mathrm{GABA}_{\mathrm{A}} \mathrm{Rs}$ and EtOH exposure/ withdrawal-induced $\mathrm{GABA}_{\mathrm{A}} \mathrm{R}$ plasticity, including alterations in responsiveness of extrasynaptic and postsynaptic $\mathrm{GABA}_{\mathrm{A}} \mathrm{Rs}$ to acute $\mathrm{EtOH}$ and, most importantly, increases in $\mathrm{GABA}_{\mathrm{A}} \mathrm{R} \alpha 4$ subunit expression in hippocampus and cultured neurons. DHM anti-alcohol effects on both behavior and CNS neurons were antagonized by flumazenil (10 mg/kg in vivo; $10 \mu \mathrm{m}$ in vitro), the benzodiazepine (BZ) antagonist. DHM competitively inhibited BZ-site $\left[{ }^{3} \mathrm{H}\right]$ flunitrazepam binding $\left(\mathrm{IC}_{50}, 4.36 \mu \mathrm{M}\right)$, suggesting DHM interaction with EtOH involves the $\mathrm{BZ}$ sites on $\mathrm{GABA}_{\mathrm{A}} \mathrm{Rs}$. In summary, we determined DHM anti-alcoholic effects on animal models and determined a major molecular target and cellular mechanism of DHM for counteracting alcohol intoxication and dependence. We demonstrated pharmacological properties of DHM consistent with those expected to underlie successful medical treatment of AUDs; therefore DHM is a therapeutic candidate.
\end{abstract}

\section{Introduction}

Alcohol (EtOH) use disorders (AUDs) represent a substantial public health problem worldwide. Over 76 million people present with AUDs; 2.5 million deaths were attributed to alcohol (World Health Organization, 2010). The development of AUDs involves repeated alcohol use leading to tolerance and withdrawal syndrome (AWS), including hyperexcitability, distress, anxiety, insomnia, agitation, occasional seizures, and dependence (Trevisan et al., 1998; Heilig et al., 2010). Only an estimated 13\% of people with identified AUDs have ever received specialty treatment due to the lack of effective medications that ameliorate AWS and cure alcohol dependence. There is an urgent need for the development of new, more effective medications (http://grants1.nih.gov/grants/guide/pa-files/PA-10-100.html).

\footnotetext{
Received Sept. 6, 2011; revised Nov. 6, 2011; accepted Nov. 9, 2011.

Author contributions: X.M.S., I.S., R.W.O., and J.L. designed research; Y.S., A.K.L., C.G., and J.L. performed research; Y.S., A.K.L., C.G., X.M.S., and J.L. analyzed data; Y.S., X.M.S., I.S., R.W.O., and J.L. wrote the paper.

This work was supported by United States Public Health Service Grants AA017991 (J.L.), AA07680 (R.W.O.), and AA016100 (I.S.), and Tobacco-Related Disease Research Program (California) Grant 18XT-0183 (X.M.S.). We thank Dr. Werner Sieghart for providing antibodies, Delia Tio for plasma [EtOH] assays, and Drs. Tom Otis, Jiang-hong Ye, and Martin Wallner for helpful discussions.

The authors declare no competing financial interests.

Correspondence should be addressed to Jing Liang, Department of Molecular and Medical Pharmacology, David Geffen School of Medicine, University of California, Los Angeles, Los Angeles, CA 90095. E-mail: jliang@ucla.edu. DOI:10.1523/JNEUROSCI.4639-11.2012

Copyright $\odot 2012$ the authors $\quad 0270-6474 / 12 / 320390-12 \$ 15.00 / 0$
}

Although EtOH ingestion impacts most organ systems, its effects on the brain are of vital importance to AUDs, given EtOH's many neuropharmacological actions, including its intoxicating, sedative, anxiolytic, reinforcing, and addictive properties (Hobbs et al., 1996; Paul, 2006). EtOH alters the balance between GABA, the primary inhibitory neurotransmitter, and glutamate, the major excitatory neurotransmitter in CNS underlying the development of AUDs (Mukherjee et al., 2008). GABA $\mathrm{A}_{\mathrm{A}}$ receptor $\left(\mathrm{GABA}_{\mathrm{A}} \mathrm{R}\right)$-mediated inhibition is enhanced by acute $\mathrm{EtOH}$ (Aguayo et al., 2002; Koob, 2004; Lovinger and Homanics, 2007), with effects reported for both presynaptic increased GABA release (Siggins et al., 2005; Weiner and Valenzuela, 2006) and direct enhancement of $\mathrm{GABA}_{\mathrm{A}}$ Rs in the postsynaptic cell (Morrow et al., 1990; Boehm et al., 2004; Wallner and Olsen, 2008). $\mathrm{GABA}_{\mathrm{A}} \mathrm{Rs}$ formed from a family of subunits exhibit different sensitivities to $\mathrm{EtOH}$ and are located either in postsynaptic or extrasynaptic membranes; this is a dynamic state with regulated trafficking between pools (Olsen and Homanics, 2000; Wallner et al., 2003; Lovinger and Homanics, 2007). Extrasynaptic $\mathrm{GABA}_{\mathrm{A}}$ Rs are sensitive to blood EtOH concentrations reached during social drinking (Devaud et al., 1997; Wei et al., 2004; Hanchar et al., 2005; Liang et al., 2006). Chronic EtOH administration to rats produces profound $\mathrm{GABA}_{\mathrm{A}} \mathrm{R}$ plasticity, which contributes critically to $\mathrm{EtOH}$ withdrawal and dependence (Liang et al., 2004, 2006, 2009; Morrow et al., 2008; Olsen and Spigelman, 2012). After acute EtOH exposure, some $\mathrm{GABA}_{\mathrm{A}} \mathrm{Rs}$ are down- 
regulated rapidly, which, with compensatory $\mathrm{GABA}_{\mathrm{A}} \mathrm{R}$ plasticity, produces altered physiology and pharmacology consistent with signs of tolerance and withdrawal exhibited in vivo (Liang et al., 2007; Shen et al., 2011). EtOH-induced behavioral changes and $\mathrm{GABA}_{\mathrm{A}} \mathrm{R}$ plasticity can be used as a screen for drugs that ameliorate AUDs.

Hovenia dulcis is listed among the premier anti-hangover herbal medicines in China's first pharmacopoeia, the Tang Materia Medica (Su, 659). Hovenia extracts ameliorate alcoholinduced liver injuries (Du et al., 2010) and relieves hangover, partly by promoting EtOH elimination via enhancement of alcohol dehydrogenase $(\mathrm{ADH})$ and acetaldehyde dehydrogenase (ALDH) activity (Kim et al., 2000; Chen et al., 2006). However, its true efficacy, active constituents, and mechanisms of action have not been critically examined.

Here we demonstrate that dihydromyricetin $[(2 R, 3 R)-3,5,7-$ trihydroxy-2-(3,4,5-trihydroxyphenyl)-2,3-dihydrochromen-4one (DHM)], a flavonoid component from Hovenia, is highly effective in counteracting acute EtOH intoxication, EtOH exposure/ withdrawal-induced $\mathrm{GABA}_{\mathrm{A}} \mathrm{R}$ plasticity and AWS symptoms, as well as reducing excessive $\mathrm{EtOH}$ consumption. We provide strong evidence that DHM is a candidate for development as a novel AUD therapy.

\section{Materials and Methods}

Animals. All animal experiments followed the Institutional Animal Care and Use Committee approved protocols. Male adult Sprague Dawley rats (200-250 g; Harlan Laboratory) were used in the study. Pregnant Sprague Dawley rats (250-300 g; Charles River Laboratories) were used for primary neuron cultures. The total animals we used in this study were 315 male rats and 5 pregnant rats. For EtOH administration, rats received intraperitoneal injection of EtOH ( $3 \mathrm{~g} / \mathrm{kg}$ as a $15 \% \mathrm{w} / \mathrm{v}$ solution in $0.9 \%$ saline and $4 \mathrm{~g} / \mathrm{kg}$ as a $20 \% \mathrm{w} / \mathrm{v}$ solution in $0.9 \%$ saline; both injection volumes were $2 \mathrm{ml} / 100 \mathrm{~g}$ body weight; Pharmco Products) or received a single dose of $\mathrm{EtOH}(5 \mathrm{~g} / \mathrm{kg}$, gavage). All of the intraperitoneal injections were performed with a single injection at a final volume of $2 \mathrm{ml} / 100 \mathrm{~g}$ body weight in each rat (with a final dose amount of each drug reported in Results).

Chemicals. DHM was purchased from ZR Chemical (CAS \#27200-12$0)$. It was purified by HPLC (98\%) from natural products. Other chemicals including flumazenil, picrotoxin, and bicuculline were purchased from Sigma-Aldrich. Stock solutions of DHM and flumazenil were made with dimethyl sulfoxide (DMSO; except for the two-bottle choice experiments described below, the solution was made in drinking water) and diluted to final concentration in saline for injection or oral administration. Injection volume was $2 \mathrm{ml} / 100 \mathrm{~g}$ body weight. The final DMSO concentration did not exceed $0.01 \%$.

Clinically, the Hovenia dosage range used for hangover is $100-650$ $\mathrm{mg} / \mathrm{kg}$ (Li, 1590). Total flavonoids purified from Hovenia are $4.53 \%$ of the extract, of which DHM accounts for $\sim 40 \%$, suggesting a $1-15 \mathrm{mg} / \mathrm{kg}$ dose for behavioral assays.

Loss of righting reflex assay. After drug injection (intraperitoneally), a timer was started and rats were placed in the supine position in a $\mathrm{V}$-shaped support. Loss of righting reflex (LORR) onset time was taken from the endpoint of injection to the start of LORR. LORR ended when the animal was able to flip over three times in $30 \mathrm{~s}$.

Elevated plus maze assay. Anxiety associated with $\mathrm{EtOH}$ withdrawal was measured on an elevated plus maze (Liang et al., 2004). The maze was elevated $1 \mathrm{~m}$ above the floor and contained four $51-\mathrm{cm}$-long, $11.5-\mathrm{cm}-$ wide arms arranged at right angles. The closed arms had opaque walls 30 $\mathrm{cm}$ high, extending the length of the arm. At the time of the test, each animal was placed in the center of the maze facing an open arm and allowed to explore for a $5 \mathrm{~min}$ session. During this $5 \mathrm{~min}$ test session, the animal's behavior (e.g., number of arm entries and time spent in each arm per entry) was recorded on a camcorder.

Pentylenetetrazol-induced seizure test. Pentylenetetrazol (PTZ) dose used in this study $(42 \mathrm{mg} / \mathrm{kg}$ in $0.9 \%$ saline; injection volume was 1 $\mathrm{ml} / 100 \mathrm{~g}$ body weight) was determined as the dose that induced seizures in $75 \%$ of naive rats. Briefly, after intraperitoneal injection of PTZ, the time to onset and the duration of tonic-clonic seizures was determined (Liang et al., 2004).

The researchers who did the animal behavior experiments were blind to treatment groups. Animals were used once only for any determination.

Voluntary EtOH consumption measurement (two-bottle choice, intermittent access to EtOH paradigm). All fluids were presented in $100 \mathrm{ml}$ graduated glass cylinders with stainless-steel drinking spouts inserted 15 min after the lights went off in the reversed light/dark cycle room. Bottles were weighed $30 \mathrm{~min}$ and $24 \mathrm{~h}$ after the fluids were presented. Every rat was weighed daily to monitor health and calculate the grams of EtOH intake per kilogram of body weight.

At the beginning of two-bottle choice paradigm, naive rats were trained to have free two-bottle choice, intermittent access to $20 \%(\mathrm{w} / \mathrm{v})$ $\mathrm{EtOH}$ and water (E/water), EtOH plus DHM $(0.05 \mathrm{mg} / \mathrm{ml}$, dissolved in drinking water (E+D/water), DHM and water (D/water), or water/water for 2 weeks with three $24 \mathrm{~h}$ sessions per week (Mondays, Wednesdays, and Fridays) (Li et al., 2010). All drinking liquids contained 2 packets of sweetener per liter ( 1 packet Equal 0 calorie sweetener contains $1 \mathrm{~g}$ dextrose with maltodextrin and aspartame) for the first week and then decreased to 1 packet of sweetener per liter for the second week. After 2 weeks of training (started at the third week), rats were given two-bottle choice access to $\mathrm{E} /$ water, $\mathrm{E}+\mathrm{D}$ /water, or $\mathrm{D} /$ water without any sweetener in all drinking liquids for two-bottle choice. Rats had unlimited access to two bottles of water between the $\mathrm{EtOH}$ access periods. The placement of the EtOH bottle was alternated each EtOH drinking session to control for side preferences. Rats were maintained on the $20 \%$ EtOH intermittentaccess, two-bottle choice paradigm for 6 weeks $(21 \mathrm{EtOH}$ access sessions). Half of E/water group had DHM added to the EtOH bottle beginning at the seventh week. The rest of the E/water group continued EtOH access sessions. The experiment period was 10 weeks total. EtOH consumption was expressed as grams of EtOH consumed per kilogram of body weight. Animals in the control group had ad libitum access to two bottles of water.

Plasma EtOH concentration assay. Blood samples from the tail vein of rats at different time points $(0,5,30,60,90$, and $180 \mathrm{~min})$ after EtOH or $\mathrm{E}+\mathrm{D}$ intraperitoneal injections were collected for plasma EtOH concentrations (plasma $[\mathrm{EtOH}]$ ) assays. Briefly, the rat was put into a restraint tube and its tail was warmed at $\sim 37^{\circ} \mathrm{C}$. The tail vein at the tip of the rail was punched with a sharp blade. Approximately $0.2 \mathrm{ml}$ venous blood was dropped to a capillary blood collection tube containing lithium heparin (Ram Scientific). Blood samples were centrifuged at $2500 \mathrm{rpm}$ for 20 min. The supernatant was collected and stored at $-80^{\circ} \mathrm{C}$ until assay. The EtOH content of each blood sample was measured in duplicate along with $\mathrm{EtOH}$ standards using the alcohol oxidase reaction procedures (GM7 Micro-Stat; Analox Instruments) (Liang et al., 2007).

For plasma $[\mathrm{EtOH}]$ assay of two-bottle choice, blood samples were collected from the rats 30, 45, 60, and $100 \mathrm{~min}$ after the voluntary EtOH two-bottle choice procedure (E/water and $\mathrm{E}+\mathrm{D} /$ water groups). The sample preparations were the same as described above.

Primary hippocampal neuron culture. Hippocampal neurons from embryonic day 18 rats were prepared by papain dissociation (Worthington Biochemical) and cultured in Neurobasal medium (Invitrogen) and B27 supplement as reported previously (Shen et al., 2011). Briefly, embryos were removed from maternal rats anesthetized with isoflurane and euthanized by decapitation. Hippocampi were dissected and placed in $\mathrm{Ca}^{2+}$ - and $\mathrm{Mg}^{2+}$-free HEPES-buffered HBSS, pH 7.45. Tissues were dissociated by papain digestion followed by trituration through a Pasteur pipette and papain inhibitor treatment. Cells were pelleted and resuspended in Neurobasal medium containing 2\% B27 serum-free supplement, $100 \mathrm{U} / \mathrm{ml}$ penicillin, $100 \mu \mathrm{g} / \mathrm{ml}$ streptomycin, $0.5 \mathrm{~mm}$ glutamine (all from Invitrogen), and $10 \mu \mathrm{M}$ glutamate (Sigma).

Dissociated cells were then plated at a density of $0.3 \times 10^{5} \mathrm{cells} / \mathrm{cm}^{2}$ onto $12 \mathrm{~mm}$ round coverslips in 24 -well plates (for patch-clamp recording) and/or at a density of $0.5 \times 10^{5} \mathrm{cells} / \mathrm{cm}^{2}$ in six-well plates (for Western blot and biotinylation assays) coated with poly-D-lysine (Sigma; $50 \mu \mathrm{g} / \mathrm{ml}$ ). Cultures were kept at $37^{\circ} \mathrm{C}$ in a $5 \% \mathrm{CO}_{2}$ humidified incuba- 
tor. Thereafter, one-third to one-half of the medium was replaced twice a week with Neurobasal culture medium containing 2\% B27 supplement and $0.5 \mathrm{~mm}$ glutamine.

$\mathrm{EtOH}$ or vehicle exposure. At $24 \mathrm{~h}$ before whole-cell patch-clamp recording and/or biochemical experiments, half of the medium of cultured neurons [day in vitro 13 (DIV13)-DIV14] was replaced with Neurobasal culture medium containing $120 \mathrm{~mm} \mathrm{EtOH}$ (the final EtOH concentration was $60 \mathrm{~mm}$ ) for $30 \mathrm{~min}$, and then the entire medium replaced with half fresh Neurobasal culture medium plus half original medium (kept in the dishes, at $37^{\circ} \mathrm{C}$ ). The same procedure was used for $\mathrm{EtOH}+\mathrm{DHM}$ (final concentration, $0.1 \mu \mathrm{M}$ ) and DHM-alone treatments. Control neurons were treated with the corresponding vehicles. Neurons were maintained in the incubator until use.

Whole-cell patch-clamp recordings from slices and cultured neurons. Transverse slices $(400 \mu \mathrm{m})$ of dorsal hippocampus were obtained from adult rats using a Vibratome (VT 100; Technical Products International). Slices were perfused continuously with artificial CSF (ACSF) composed of the following (in $\mathrm{mm}$ ): $125 \mathrm{NaCl}, 2.5 \mathrm{KCl}, 2$ $\mathrm{CaCl}_{2}, 2 \mathrm{MgCl}_{2}, 26 \mathrm{NaHCO}_{3}$, and $10 \mathrm{D}$-glucose. The ACSF was bubbled continuously with $95 \% \mathrm{O}_{2} / 5 \% \mathrm{CO}_{2}$ to ensure adequate oxygenation of slices and a $\mathrm{pH}$ of 7.4 , and kept at $34 \pm 0.5^{\circ} \mathrm{C}$ for perfusion. Patch electrodes were pulled from thin-wall borosilicate glass pipettes with resistances of 5.5-7.5 $\mathrm{M} \Omega$ and were filled with internal solution containing the following (in $\mathrm{mm}$ ): $137 \mathrm{CsCl}, 2 \mathrm{MgCl}_{2}, 1 \mathrm{CaCl}_{2}, 11$ EGTA, 10 HEPES, and 3 ATP, pH adjusted to 7.30 with CsOH. Recordings targeted dentate gyrus granule cells (DGCs) of hippocampal slices (Liang et al., 2007).

Cultured neurons were transferred to a chamber perfused with an extracellular solution containing the following (in $\mathrm{mm}$ ): $137 \mathrm{NaCl}, 5 \mathrm{KCl}$, $2 \mathrm{CaCl}_{2}, 1 \mathrm{MgCl}_{2}, 20$ glucose, and 10 HEPES, pH 7.40 (room temperature), and visualized with an inverted microscope (TE200; Nikon). Recordings targeted pyramidal cells (Shen et al., 2011).

Neurons were whole-cell voltage-clamped at a holding potential of $-70 \mathrm{mV}$ with an Axopatch 200B amplifier (Molecular Devices). Access resistances were $<25 \mathrm{M} \Omega$ before electrical compensation by $\sim 70 \%$. Intracellular signals were low-pass filtered at $3 \mathrm{kHz}$ and digitized at a sampling frequency of $20 \mathrm{kHz}$. Pharmacologically isolated $\mathrm{GABA}_{\mathrm{A}} \mathrm{R}$-mediated miniature IPSCs (mIPSCs) were recorded by adding tetrodotoxin (TTX; $0.5 \mu \mathrm{M}$ ), D(-)-2-amino-5phosphonopentanoate (AP-V; $40 \mu \mathrm{M})$, 6-cyano-7-nitroquinoxaline-2,3-dione (CNQX, $10 \mu \mathrm{M})$, and [S-( $\left.\left.\mathrm{R}^{\star}, \mathrm{R}^{\star}\right)\right]$-[3-[[1-(3,4-Dichlorophenyl)ethyl] amino]-2hydroxypropyl](cyclohexylmethyl) phosphinic acid (CGP54626; $1 \mu \mathrm{M}$, $\mathrm{GABA}_{\mathrm{B}} \mathrm{R}$ antagonist) to the ACSF (or extracellular solution for cultured neurons) from stock solutions. Stock solutions of CGP54626 were made with DMSO. Final concentrations of DMSO did not exceed $0.01 \%$ in the recording chamber. For the cultured neurons, control and drug-containing solutions were delivered through a removable tip that was positioned close to the soma of target neurons with a Valvelink 8.02 fast-exchange perfusion system (AutoMate Scientific). The flow rate of the perfusion system was $\sim 0.3-0.5 \mathrm{ml} / \mathrm{min}$, and the total volume of the recording chamber was $3 \mathrm{ml}$. For GABA concentration-response curves, evoked $\mathrm{GABA}_{\mathrm{A}} \mathrm{R}$ currents were recorded during acute applications of GABA or DHM onto neurons through a removable pipette tip using a Valvelink 8.02 (Liang et al., 2007; Shen et al., 2011).

Detection and analysis of mIPSCs and GABA $A_{A}$-mediated tonic currents. Briefly, the recordings were low-pass filtered off-line (Clampfit software, version 10.3) at $2 \mathrm{kHz}$. The mIPSCs were detected (Mini Analysis Program, version 6.0.7) with threshold criteria of an $8 \mathrm{pA}$ amplitude and $20 \mathrm{pA}$ * $\mathrm{ms}$ area. The frequency of mIPSCs was determined from all automatically detected events in a given $100 \mathrm{~s}$ recording period. For kinetic analysis, only single-event mIPSCs with a stable baseline, sharp rising phase (10 to $90 \%$ rise time), and exponential decay were chosen during visual inspection of the recording trace. Double- and multiple-peak mIPSCs were excluded. At least 100 individual mIPSC events were recorded under each experimental condition. The mIPSC kinetics were obtained from analysis of the averaged chosen single events aligned with half rise time in each cell. Decay time constants were obtained by fitting a double exponential to the falling phase of the averaged mIPSCs.

The $\mathrm{GABA}_{\mathrm{A}} \mathrm{R}$-mediated tonic current $\left(I_{\text {tonic }}\right)$ magnitudes were obtained from the averaged baseline current of a given recording period.
Two methods were used to measure $I_{\text {tonic }}$ : shifts in the baseline current and changes in baseline noise. The baseline noise arises from the recording apparatus (machine noise) and opening and closing of chloride channels and receptors at any holding potential. When bicuculline $(10 \mu \mathrm{M})$ or picrotoxin $(100 \mu \mathrm{M})$, both selective $\mathrm{GABA}_{\mathrm{A}} \mathrm{R}$ inhibitors, is applied, both the baseline current and baseline noise are diminished. The baseline noise was quantified by measuring the root mean square (RMS) noise using the RMS analysis routines packaged with the Mini Analysis program (Synaptosoft). RMS noise was measured only in the absence of phasic synaptic currents after bicuculline or picrotoxin blocked phasic synaptic currents (Liang et al., 2004; Mangan et al., 2005; Shen et al., 2011). The investigator performing the recordings and mIPSC analysis was blind to the treatments the rats received.

Western blots. Hippocampal tissues from rats were lysed in RIPA buffer containing $1 \%$ Triton X-100, 0.1\% SDS, and the following (in $\mathrm{mm}$ ): 50 $\mathrm{Na}_{3} \mathrm{PO}_{4}, 150 \mathrm{NaCl}, 2 \mathrm{EDTA}, 50 \mathrm{NaF}, 10$ sodium pyrophosphate, 1.0 sodium orthovanadate, 1.0 phenylmethylsulfonyl fluoride, and complete protease inhibitor cocktail (Roche). The lysate was centrifuged for 15 $\min \left(14,000 \times g, 4^{\circ} \mathrm{C}\right)$ and the supernatant collected for Western blot analysis. Western blots were performed using rabbit anti-GABA $\mathrm{R} \alpha 4$ (amino acids 379-421, gift from W. Sieghart, Medical University Vienna, Austria) and mouse anti- $\beta$-actin (Sigma) followed by HRPconjugated secondary antibodies. Bands were analyzed by densitometric measurements using ImageQuant 5.2 (Molecular Dynamics).

Biotinylation assay for cell-surface receptors. The biotinylation procedure was performed as described previously (Shen et al., 2011). Briefly, neurons were placed on ice, washed, and then incubated for $30 \mathrm{~min}$ with PBS containing $1 \mathrm{mg} / \mathrm{ml}$ sulfo-NHS-LC-biotin (ProteoChem). After quenching the biotin reaction with Tris-buffered saline, neurons were lysed in modified RIPA buffer. After centrifugation $10 \%$ of the supernatant was removed to measure $\beta$-actin. The remaining supernatant was incubated with $60 \mu \mathrm{l}$ of Neutravidin agarose (Pierce Chemical). Agarosebound proteins were taken up in SDS sample buffer and boiled. Western blots were performed as mentioned above.

Tissue preparation and $\left[{ }^{3} \mathrm{H}\right]$ flunitrazepam binding assays. Naive rat cortex was homogenized in $0.32 \mathrm{M}$ sucrose and $10 \mathrm{~mm}$ HEPES buffer, $\mathrm{pH}$ 7.4 , and centrifuged at $650 \times g$ at $4^{\circ} \mathrm{C}$. The subsequent supernatant was centrifuged at $150,000 \times g$ to collect the desired membrane-containing pellet. The pellet was washed and centrifuged two more times, first using ice-cold water and second using membrane buffer containing the following (in mM): $50 \mathrm{KH}_{2} \mathrm{PO}_{4}, 1$ EDTA, 2 benzamidine $\mathrm{HCl}, 0.5 \mathrm{DTT}, 0.1$ benzethonium $\mathrm{HCl}, 0.01 \%$ bacitracin, and $0.2 \mathrm{PMSF}, \mathrm{pH}$ 7.4. The resulting pellet was frozen. On the day of binding assay, the pellet was homogenized in assay buffer containing $50 \mathrm{mM} \mathrm{KH}_{2} \mathrm{PO}_{4}, 1 \mathrm{~mm}$ EDTA, and 200 $\mathrm{mm} \mathrm{KCl}, \mathrm{pH} 7.4$, centrifuged, and resuspended in fresh assay buffer to a final protein concentration of $1 \mathrm{mg} / \mathrm{ml}$. [ $\left.{ }^{3} \mathrm{H}\right]$ flunitrazepam $(85.2 \mathrm{Ci} /$ mmol; PerkinElmer), brain homogenate, and DHM were placed into glass culture tubes for a final assay volume of $0.5 \mathrm{ml}$. The solutions were vortexed and allowed to incubate on ice for $30 \mathrm{~min}$ and filtered onto Whatman GF/B filter paper using a Brandel cell harvester M-24R. Filters were placed into minivials (Fisher Scientific) and $2.5 \mathrm{ml}$ scintillation fluid (MP Biomedicals) and shaken for $1 \mathrm{~h}$. Samples were counted in a Beckman LS-3801 liquid scintillation counter. Specific binding was defined as the total amount bound (zero unlabeled ligand) minus the binding in the presence of $10 \mu \mathrm{M}$ final concentration flurazepam (Sigma). Data were analyzed with GraphPad Prism 4.0 software to determine $\mathrm{IC}_{50}$ value (one-site competition equation) and Hill slope (sigmoidal dose-response equation). Experiments were conducted in triplicate (Li et al., 2010).

Statistical analysis. SigmaPlot, SigmaStat (Systat Software) and GraphPad Prism 4.0 were used for data display and statistical analysis. Data are expressed as the mean \pm SEM. A $t$ test, one-way or one-way repeatedmeasurement (RM) ANOVA followed by multiple comparison analyses based on Dunnett's method, or two-way or two-way RM ANOVA followed by post hoc multiple comparison analyses based on the Holm-Sidak method were used to determine significant levels between treatments and controls. 


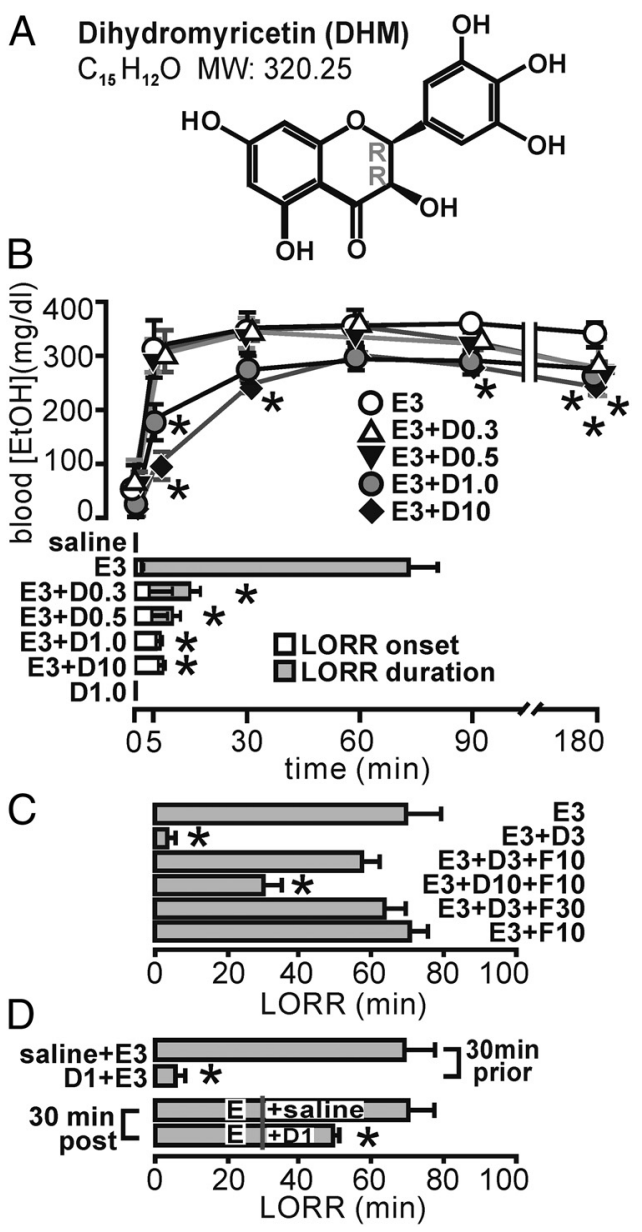

Figure 1. DHM counteracts EtOH intoxication and the effect of DHM is antagonized by flumazenil. $\boldsymbol{A}$, Chemical structure of DHM. $\boldsymbol{B}$, Top, Plasma [EtOH] assay associated with EtOH-induced LORR. The $x$-axis shows time points after intraperitoneal injection of EtOH ( $3 \mathrm{~g} / \mathrm{kg}$ ) or coapplication of DHM $(0.3,0.5,1$, and $10 \mathrm{mg} / \mathrm{kg}$ ) with EtOH ( $n=3-4$ rats per group). Zero represents the time from intraperitoneal injection of EtOH or $\mathrm{E}+\mathrm{D}$ to complete sample venous blood collection (usually it took 0 to $3 \mathrm{~min}$ ). Bottom, E3 induced LORR, while concurrent injection of DHM with EtOH (E3+D0.3, E3+D0.5, E3 + D1, and E3+D10) increased LORR onset time and greatly reduced the duration of $L O R R$ dose dependently. DHM (D1) as the saline control did not induce LORR ( $n=4-12$ rats per group). *Statistical significance versus the E3 group. C, Coinjection of EtOH and DHM ( $3 \mathrm{mg} / \mathrm{kg} ; \mathrm{E3}+\mathrm{D} 3)$ greatly reduced the E3-induced LORR. Concurrent injection of flumazenil $(10 \mathrm{mg} / \mathrm{kg}$; F10) with EtOH and DHM (E3 + D3 + F10) reversed the DHM effect. When we increased the dose of DHM to $10 \mathrm{mg} / \mathrm{kg}$ (E3+D10+F10), flumazenil partially reversed the effect of DHM. When we increased the dose of flumazenil to $30 \mathrm{mg} / \mathrm{kg}$ $(\mathrm{E} 3+\mathrm{D} 3+\mathrm{F} 30)$, stronger antagonism of DHM was observed. Coinjection of flumazenil with $\mathrm{EtOH}(\mathrm{E} 3+\mathrm{F} 10)$ did not alter LORR duration ( $n=5-13$ rats per group). $\boldsymbol{D}$, DHM application 30 min before EtOH injection counteracted EtOH-induced LORR, whereas 30 min after EtOH injection (indicated as gray lines), DHM injection reduced the residue of LORR ( $n=5$ rats per group).

\section{Results}

DHM counteracts EtOH intoxication, and this effect is antagonized by flumazenil

We examined DHM effects on EtOH intoxication (LORR) in rats. Studies on the neuroprotective effects have shown that flavonoids, including DHM purified from Hovenia (Fig. 1A) are able to pass the blood-brain barrier (Youdim et al., 2003).

Rats were divided into seven groups and injected intraperitoneally with saline, $\mathrm{EtOH}(3 \mathrm{~g} / \mathrm{kg}$; E3), EtOH combined with DHM $[0.3 \mathrm{mg} / \mathrm{kg}(\mathrm{E} 3+\mathrm{D} 0.3), 0.5 \mathrm{mg} / \mathrm{kg}(\mathrm{E} 3+\mathrm{D} 0.5), 1 \mathrm{mg} / \mathrm{kg}$ (E3+D1), and $10 \mathrm{mg} / \mathrm{kg}(\mathrm{E} 3+\mathrm{D} 10)]$, or DHM (D1) alone (single injection at a volume of $2 \mathrm{ml} / 100 \mathrm{~g}$ body weight). The onset of LORR induced by E3 was $1.8 \pm 0.2 \mathrm{~min}$, while DHM dose- dependently increased LORR onset $(n=4-12$ rats per group; one-way ANOVA; $F_{(3,25)}=10.64 ; p<0.001$; statistical significance vs E3 group; Fig. $1 B$ ). E3 induced $73.6 \pm 8.0 \mathrm{~min}$ LORR; DHM dose-dependently reduced LORR $(n=4-12$ rats per group; one-way ANOVA; $F_{(3,22)}=26.58 ; p<0.001$; statistical significance vs E3 group; Fig. $1 B)$. DHM $(1 \mathrm{mg} / \mathrm{kg})$ as saline did not induce LORR. These results suggest that DHM counteracts acute $\mathrm{EtOH}$ intoxication.

During the LORR assay, we took venous blood samples at the various points from 0 to $180 \mathrm{~min}$ to measure plasma [EtOH] from $\mathrm{EtOH}$ and $\mathrm{E}+\mathrm{D}$ groups. $\mathrm{E} 3$ induced onset of LORR within $5 \mathrm{~min}$. Plasma [EtOH] rapidly increased for $5 \mathrm{~min}$ followed by a slower increase to around $60 \mathrm{~min}$, then $[\mathrm{EtOH}]$ declined gradually. The time course and magnitude of plasma $[\mathrm{EtOH}]$ was not affected in $\mathrm{E} 3+\mathrm{D} 0.3$ and $\mathrm{E} 3+\mathrm{D} 0.5$ groups. In $\mathrm{E} 3+\mathrm{D} 1$ and E3+D10 (DHM 1, $10 \mathrm{mg} / \mathrm{kg}$ ) groups, the rise time of plasma $[\mathrm{EtOH}]$ was slowed at early time (Fig. $1 \mathrm{~B}$ ). From 30 to $60 \mathrm{~min}$, when the rats in E3 group were sleeping while E3+D1 and $\mathrm{E} 3+\mathrm{D} 10$ groups were awake, the differences in plasma $[\mathrm{EtOH}]$ were not statistically significant between the E3 and E3+D1 groups ( $30 \mathrm{~min}, \mathrm{E} 3$ vs $\mathrm{E} 3+\mathrm{D} 1,334.9 \pm 37.8$ vs $287.7 \pm 21.5$ $\mathrm{mg} / \mathrm{dl}$; $60 \mathrm{~min}$, E3 vs E3+D1, $353.7 \pm 35.4$ vs $296.3 \pm 17.8$ $\mathrm{mg} / \mathrm{dl}$ ); a higher dose of DHM (D10) slightly decreased [EtOH] $\left(n=3-4\right.$ rats per group; two-way RM ANOVA; $F_{(4,92)}=4.28$; $p=0.025 ;$ DHM concentrations by sampling time interaction, $F_{(20,92)}=2.70, p=0.002$; post hoc analysis revealed a statistical significance at $30 \mathrm{~min}$ but not at $60 \mathrm{~min}$; significance vs E3 group; Fig. $1 B)$.

We also tested the effects of DHM on higher-dose EtOH (4 $\mathrm{g} / \mathrm{kg}$ ) as shown in Table 1 . An EtOH dose of $4 \mathrm{~g} / \mathrm{kg}$ induced $112.8 \pm 8.0 \mathrm{~min}$ LORR. DHM at dose of $1 \mathrm{mg} / \mathrm{kg}$ greatly reduced LORR to $28.2 \pm 4.0 \mathrm{~min}$. A dose of $1 \mathrm{mg} / \mathrm{kg}$ DHM did not have a significant effect on plasma $[\mathrm{EtOH}](n=4$ rats per group; twoway RM ANOVA; $p>0.05$; Table 1 ). These results suggest that DHM affects EtOH pharmacokinetics, but this effect is not sufficient to account for the DHM antagonism of EtOH-induced LORR. DHM counteracts EtOH-induced LORR even at low concentrations that do not affect the kinetics (see Discussion).

To examine the target of DHM's anti-EtOH effects, we tested flumazenil, the selective benzodiazepine (BZ) antagonist of $\mathrm{GABA}_{\mathrm{A}} \mathrm{Rs}$ (Hunkeler et al., 1981). EtOH induced $69.0 \pm 11.3$ min LORR; co-injection of DHM ( $3 \mathrm{mg} / \mathrm{kg})$ and EtOH reduced LORR to $2.7 \pm 1.7 \mathrm{~min}$ (Fig. 1 C). Flumazenil $(10 \mathrm{mg} / \mathrm{kg}$ ) reversed the DHM reduction in EtOH-induced LORR (56.1 $\pm 4.6 \mathrm{~min})$. Increasing DHM dose to $10 \mathrm{mg} / \mathrm{kg}$ decreased the flumazenil effect $(29.3 \pm 4.8 \mathrm{~min})$, while increasing the flumazenil dose to 30 $\mathrm{mg} / \mathrm{kg}$ increased its antagonism of the DHM effect (58.2 \pm 3.9 $\mathrm{min}$ ). Flumazenil coinjected with EtOH did not alter LORR compared with the E3 group ( $n=5-13$ rats; one-way ANOVA; $F_{(5,34)}$ $=16.34 ; p<0.001$; statistical significance vs E3 group; Fig. $1 C$ ). These results suggest that $\mathrm{GABA}_{\mathrm{A}} \mathrm{Rs}$ play a major role in the behavioral effects of EtOH-induced LORR in vivo. Flumazenil competitively antagonizes DHM effects on EtOH-induced LORR. In addition, the results suggest that the interactions of DHM and $\mathrm{EtOH}$ involve DHM action at $\mathrm{GABA}_{\mathrm{A}} \mathrm{R} \mathrm{BZ}$ sites that may underlie DHM therapeutic effects on EtOH intoxication.

We further tested whether DHM application before or after $\mathrm{EtOH}$ exposure would affect EtOH-induced LORR. Thirty minutes before EtOH injection $(\mathrm{D} 1+\mathrm{E})$, DHM reduced LORR to $8.2 \pm 4.1 \mathrm{~min}(n=5$ rats per group; $t$ test; $t=15.7 ; \mathrm{df}=4 ; p<$ 0.001 ; Fig. $1 D$ ). Thirty minutes after injection of EtOH that induced LORR, LORR went on for an additional $42 \pm 9.1 \mathrm{~min}$ in rats injected with saline, while injection of DHM reduced the 
Table 1. The effects of $1 \mathrm{mg} / \mathrm{kg}$ DHM on $4 \mathrm{~g} / \mathrm{kg}$ EtOH-induced blood [EtOH] kinetics and LORR duration

\begin{tabular}{|c|c|c|c|c|c|c|c|}
\hline & & Plasma [EtOH] & ng time points ( & & & & \\
\hline & LORR duration (min) & $0^{a}$ & 5 & 30 & 60 & 90 & 180 \\
\hline E4 & $112.8 \pm 8.0$ & $143.3 \pm 23.4$ & $365.5 \pm 7.7$ & $379.5 \pm 5.9$ & $372.8 \pm 5.4$ & $361.6 \pm 8.2$ & $324.6 \pm 21.4$ \\
\hline $\mathrm{E} 4+\mathrm{D} 1$ & $28.2 \pm 4.0$ & $156.4 \pm 18.0$ & $292.8 \pm 30.1$ & $322.2 \pm 15.7$ & $353.8 \pm 0.9$ & $347.7 \pm 9.4$ & $305.4 \pm 28.5$ \\
\hline D100 & $2.9 \pm 1.3$ & & & & & & \\
\hline D300 & $9.8 \pm 4.3$ & & & & & & \\
\hline $\mathrm{F} 20$ & 0 & & & & & & \\
\hline $\mathrm{F} 200$ & 0 & & & & & & \\
\hline
\end{tabular}

High doses of DHM alone induced short-time LORR, while high dose flumazenil alone did not induced LORR. Data (mean \pm SEM) were obtained from naive rats that received intraperitoneal injections of $4 \mathrm{~g} / \mathrm{kg}$ EtOH (E4), coinjection of DHM $(1 \mathrm{mg} / \mathrm{kg}$ ) with Et0H (E4+D1), $100 \mathrm{mg} / \mathrm{kg}$ DHM (D100), $300 \mathrm{mg} / \mathrm{kg}$ DHM (D300), $20 \mathrm{mg} / \mathrm{kg}$ flumazenil (F20), or $200 \mathrm{mg} / \mathrm{kg}$ flumazenil (F200) alone ( $n=8-10 \mathrm{rats} / \mathrm{group})$.

${ }^{a} \mathrm{~A}$ value of 0 represents the time from intraperitoneal injection of $\mathrm{Et} O \mathrm{H}$ or $\mathrm{E}+\mathrm{D}$ to complete sample venous blood collection ( 0 to $3 \mathrm{~min}$ ).

remaining LORR to $19 \pm 1.0 \min (n=4$ rats per group; $t$ test; $\mathrm{df}=3 ; t=14.2 ; p<$ $0.001 ;$ Fig. 1D). These results suggest DHM effectively ameliorates moderate to high-dose EtOH intoxication even when it is administered $30 \mathrm{~min}$ before or $30 \mathrm{~min}$ after $\mathrm{EtOH}$ exposure.

We tested high doses of DHM (doses hundreds-fold higher than that for its antagonistic effects on EtOH intoxication). DHM doses of 100 and $300 \mathrm{mg} / \mathrm{kg}$ induced only $2.9 \pm 1.3$ and $9.8 \pm 4.3 \mathrm{~min}$ LORR, respectively ( $n=8-10$ rats per group; Table 1), suggesting that DHM is not merely a typical benzodiazepine. High doses of flumazenil (20 and $200 \mathrm{mg} / \mathrm{kg}$ ) did not induce LORR ( $n=5$ rats per group; Table 1).

\section{DHM ameliorates EtOH withdrawal symptoms in rats}

We examined DHM effects on EtOH withdrawal (W) symptoms in rats. Rats were divided into four groups and injected (intraperitoneally) with vehicle (V/ $\mathrm{W}), \mathrm{EtOH}(3 \mathrm{~g} / \mathrm{kg}$; E/W), EtOH combined with DHM (1 mg/kg; E+D/W), or DHM $(\mathrm{D} / \mathrm{W})$ respectively; all of the injections in the four groups were performed with a single injection at a final volume of $2 \mathrm{ml} /$ $100 \mathrm{~g}$ body weight in each rat. Then, rats were subdivided into three groups to measure signs of EtOH withdrawal at $48 \mathrm{~h}$.

Anxiety was assayed with the elevated plus maze (Fig. $2 A$ ). The V/W group spent $57.4 \pm 9.8 \%$ of total time (time in open arm, closed arm, and center; total, 5 $\min$ ) in open arms and $32.6 \pm 8.6 \%$ in closed arms. The E/W group spent a significantly shorter time in open arms and a longer time in closed arms than the $\mathrm{V} / \mathrm{W}$ group (statistical significance vs $\mathrm{V} / \mathrm{W}$ group; $n=5-6$ rats/group; Fig. $2 A$ ), while the $\mathrm{E}+\mathrm{D} / \mathrm{W}$ group spent a similar amount of time in each arm. Our two-way ANOVA analysis revealed significant DHM effects by EtOH exposure/withdrawal interaction $\left(F_{(1,22)}=5.51, p=\right.$ 0.03 for closed arm stay; $F_{(1,22)}=5.20$, $p=0.034$ for open arm). DHM alone did

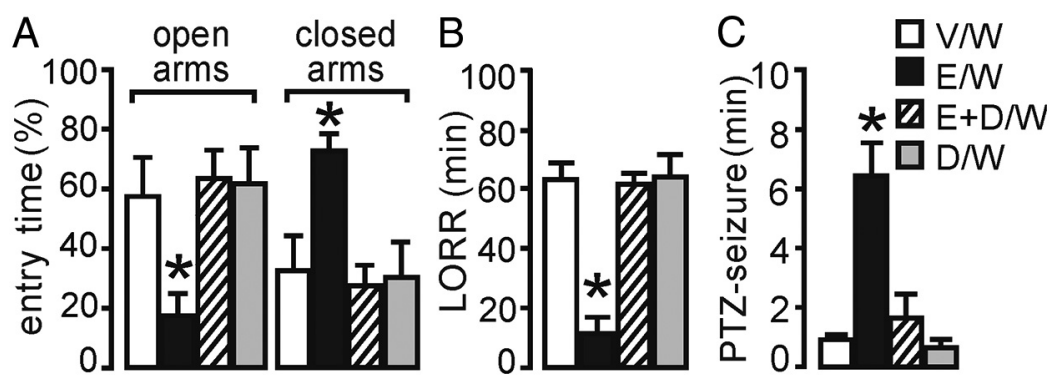

Figure 2. DHM ameliorates EtOH withdrawal symptoms in rats. Four groups of rats were injected intraperitoneally with singledose vehicle, EtOH ( $3 \mathrm{~g} / \mathrm{kg}$ ), EtOH plus DHM (1 mg/kg), or DHM alone. A, Anxiety was measured by elevated plus maze. The E/W group spent a shorter time in the open arms and longer time in the closed arms compared to the V/W group. The E+D/W group spent a similar amount of time in each arm as the V/W group ( $n=5-6$ rats per group). $\boldsymbol{B}$, Tolerance was measured by LORR. The E/W group showed a significantly shorter duration of acute EtOH-induced LORR. The E+D/W group showed no different in LORR compared with the V/W group ( $n=5$ rats per group). $C$, The E/W group increased PTZ-induced seizure duration. The E+D/W group showed similar PTZ-induced seizures as the V/W group. The D/W group showed no difference compared with the V/W group in all three assays ( $n=6-13$ rats per group). *Statistical significance versus the V/W group.
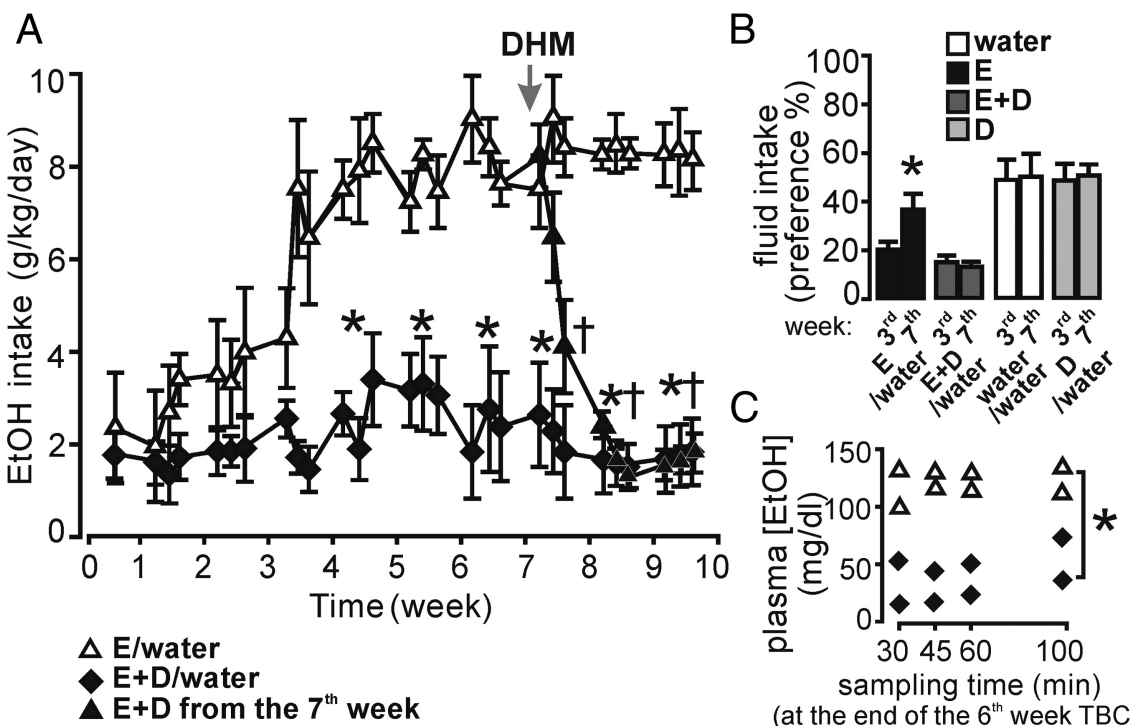

sampling time (min)

(at the end of the $6^{\text {th }}$ week TBC)

Figure 3. DHM prevents the escalation of EtOH consumption in the voluntary intermittent two-bottle choice paradigm in rats. $A$, EtOH consumption gradually escalated in the group of intermittent access to two-bottle choice of $20 \% \mathrm{EtOH} /$ water. Coadministration of DHM $(0.05 \mathrm{mg} / \mathrm{ml})$ with EtOH ( $\mathrm{E}+\mathrm{D} /$ water $)$ counteracted this increase $\left({ }^{*}\right.$, Statistical significance vs $\mathrm{E} /$ water group). The symbols are mean $\mathrm{Et} 0 \mathrm{H}$ intake (grams per kilogram per day) $\pm \mathrm{SEM}$. After 6 weeks, rats in the $\mathrm{E} /$ water group were separated into two subgroups: one continuing intermittent access $\mathrm{Et} O \mathrm{H}$ and one with intermittent access to $\mathrm{E}+\mathrm{D}$. Whereas the $\mathrm{E} /$ water group kept a high level of $\mathrm{EtOH}$ consumption, the $\mathrm{E}+\mathrm{D} /$ water group showed a great reduction in $\mathrm{E}+\mathrm{OH}$ consumption within three doses of DHM ( $t$, statistical significance between two subgroups), and became similar in EtOH consumption by the fourth dose of DHM. $B$, Fluid intake preference in the four groups at the third and the seventh weeks of two-bottle choice paradigm. The bottle containing EtOH or EtOH-DHM were marked as "drug" bottles. Fluid intake preference (percentage) was calculated: $B /(B+$ $V)^{*} 100 \%$. $B$ is fluid intake volume from the drug bottle; $V$ is fluid intake from the water bottle $\left(n=6-8\right.$ rats per group; ${ }^{*}$ statistical significance vs $\mathrm{E} 3 \mathrm{rd}$ week $\mathrm{TBC}$ ). $\mathrm{C}$, Plasma [EtOH] was measured at the end of sixth week of two-bottle choice. Blood samples were collected from the lateral tail vein after $30,45,60$, and $100 \mathrm{~min}$ from $\mathrm{E} /$ water and $\mathrm{E}+\mathrm{D} /$ water group rats $(n=2$ rats per group; ${ }^{*}$, statistical significance between $\mathrm{E} /$ water and $\mathrm{E}+\mathrm{D} /$ water). 
A

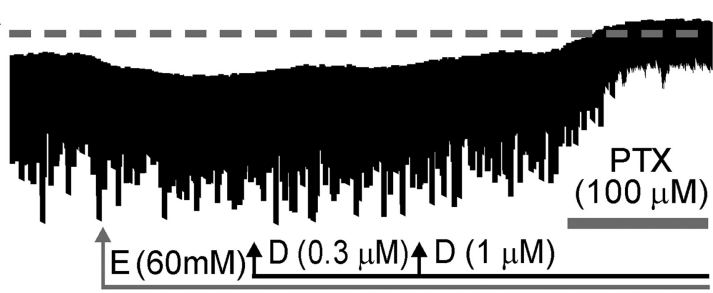

D

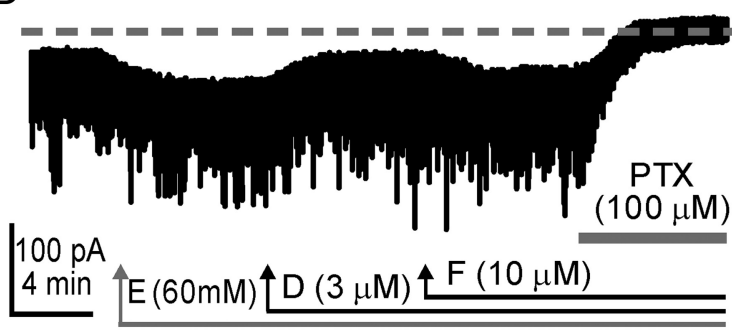

G

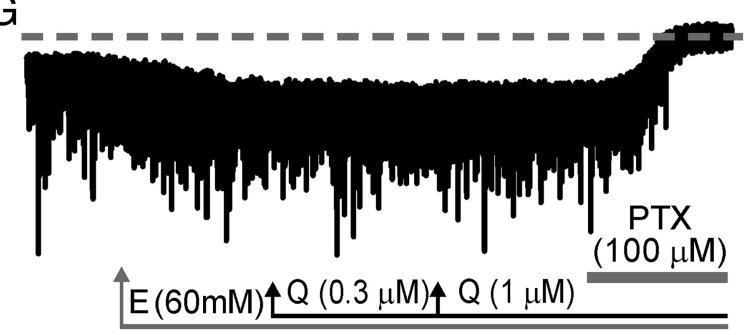

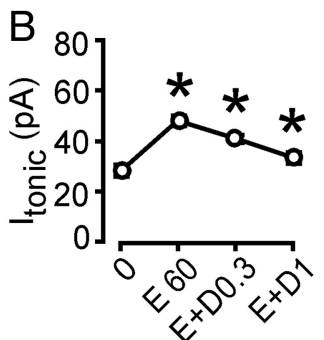
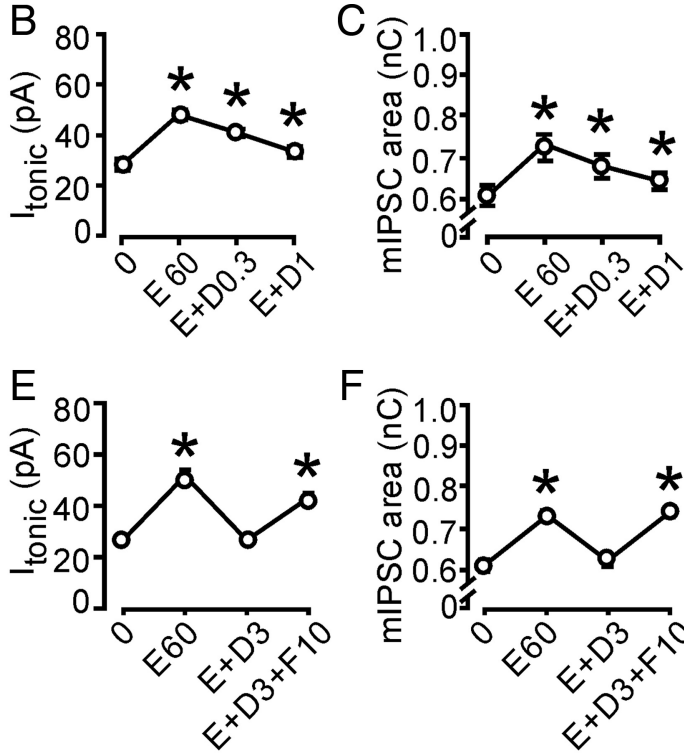

$F$

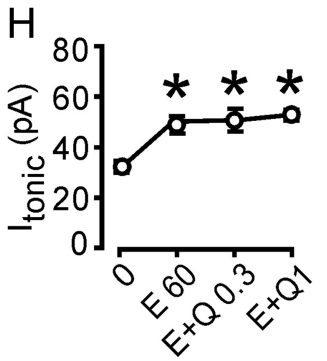

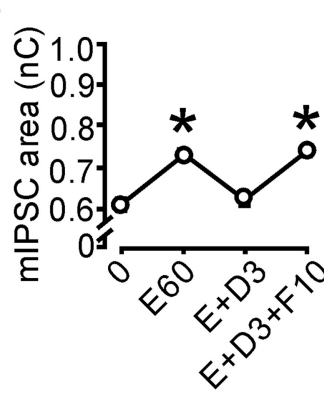

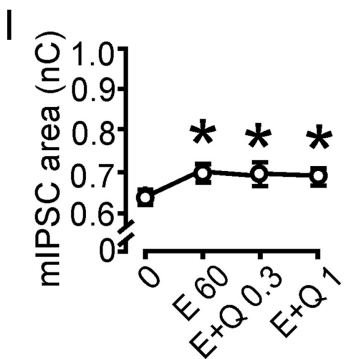

Figure 4. DHM antagonizes EtOH-induced $\mathrm{GABA}_{\mathrm{A}} \mathrm{R}$ potentiation and the effects are blocked by flumazenil. All recordings were whole-cell voltage-clamped at - $70 \mathrm{mV}$. $A$, Recording from $D G C S$ in hippocampus slices. The gray dashed lines represent the mean currents after complete blockade of all $\mathrm{GABA}_{\mathrm{A}} \mathrm{R}$ currents by picrotoxin (PTX; a GABA $\mathrm{R}$ antagonist; $100 \mu \mathrm{m}$ ) as a baseline to calculate the magnitude of $\mathrm{GABA}_{\mathrm{A}} \mathrm{R}$-mediated extrasynaptic tonic currents $\left(I_{\text {tonic }}\right)$. Bath application of EtOH $(60 \mathrm{~mm}, \mathrm{E} 60)$ increased $I_{\text {tonic }}$ and mIPSCs. DHM (0.3 and $\left.1.0 \mu \mathrm{M}\right)$ antagonized these EtOH effects. $\boldsymbol{B}, \boldsymbol{C}$, Summary of $I_{\text {tonic }}$ and mIPSC area in response to EtOH and DHM ( $n=8$ neurons $/ 3$ rats). $D, D H M(3 \mu \mathrm{M})$ antagonism on acute EtOH-induced GABA $\mathrm{A}_{\mathrm{A}}$ potentiation was reversed by $10 \mu \mathrm{M}$ flumazenil. $\boldsymbol{E}, \boldsymbol{F}$, Summary of $I_{\text {tonic }}$ and mIPSC area in response to EtOH, DHM, and flumazenil ( $n=5$ neurons $/ 3$ rats). $\mathbf{G}$, Quercetin (0.3, $1 \mu$ M) did not affect EtOH-induced enhancement of $\mathrm{GABA}_{\mathrm{A}} \mathrm{R}$-mediated currents. $\boldsymbol{H}, \mathbf{I}$, Summary of $I_{\text {tonic }}$ and mIPSC area in response to $\mathrm{EtOH}$ and quercetin $\left(n=5\right.$ neurons $/ 3$ rats). ${ }^{*}$ Statistical significance versus drug 0 .

not affect the time rats spent in either arm (Fig. $2 A)$. These data suggest that EtOH exposure/withdrawal produces anxiety, while DHM coapplication with EtOH prevents EtOH-induced anxiety; DHM alone does not affect anxiety levels.

Tolerance to acute EtOH was measured with EtOH-induced LORR (Fig. $2 B$ ). EtOH exposure/withdrawal (E/W group) reduced LORR to $10.8 \pm 3.8 \mathrm{~min}$, compared to $63.6 \pm 7.0 \mathrm{~min}$ in the V/W group (statistical significance vs V/W group; $n=5$ rats per group; Fig. $2 \mathrm{~B}$ ). Co-application of DHM and $\mathrm{EtOH}(\mathrm{E}+\mathrm{D} / \mathrm{W}$ group) reversed this effect on LORR to $61.0 \pm 3.8 \mathrm{~min}$. Two-way ANOVA analysis revealed a significant DHM effect by EtOH exposure/withdrawal interaction on $\operatorname{LORR}\left(F_{(1,19)}=15.64 ; p=\right.$ $0.001)$. DHM alone (D/W group) did not affect LORR (65.6 \pm $8.4 \mathrm{~min})$. These results suggest that a single $\mathrm{EtOH}$ exposure/removal produces tolerance to $\mathrm{EtOH}$, while DHM prevents EtOH exposure-induced tolerance to EtOH.

Hyperexcitability was assayed with PTZ-induced seizure duration (Fig. 2C). PTZ-induced $0.9 \pm 0.2 \mathrm{~min}$ seizures in the $\mathrm{V} / \mathrm{W}$ group and $6.5 \pm 1.1 \mathrm{~min}$ seizures in the $\mathrm{E} / \mathrm{W}$ group $(n=6-13$ rats per group; statistical significance vs V/W group; Fig. $2 C$ ), while seizure duration was minimized in the $\mathrm{E}+\mathrm{D} / \mathrm{W}$ group $(1.7 \pm 0.8 \mathrm{~min})$. Two-way ANOVA analysis revealed a significant DHM effect by EtOH exposure/withdrawal interaction on PTZinduced seizure $\left(F_{(1,32)}=4.37 ; p=0.046\right)$. PTZ-induced seizure duration in the DHM group was similar to the V/W group $(0.6 \pm$
$0.4 \mathrm{~min}$ ). These results suggest that EtOH exposure/withdrawal produces hyperexcitability and increases seizure susceptibility, while DHM ameliorates these effects of EtOH.

DHM reduced EtOH consumption in an intermittent voluntary alcohol intake paradigm in rats

We determined DHM effects on EtOH consumption, the most important sign of EtOH dependence. Rats were divided into four groups and offered intermittent access to a two-bottle choice of E/water, E+D/water (0.05 mg/ml DHM), D/water, or water/water, respectively. After 2 weeks, in the E/water group, EtOH consumption increased from $3.9 \pm 1.4 \mathrm{~g} / \mathrm{kg} / \mathrm{d}$ at the end of the second week to $7.4 \pm 0.6 \mathrm{~g} / \mathrm{kg} / \mathrm{d}$ at the beginning of the fourth week. In the $\mathrm{E}+\mathrm{D} /$ water group, DHM inhibited the increase in EtOH intake $(2.6 \pm 0.5 \mathrm{~g} / \mathrm{kg} / \mathrm{d}$ at the beginning of the fourth week). After 6 weeks, the E/water group was subdivided into two groups: one continued with E/water, while the other one was offered $\mathrm{E}+\mathrm{D} /$ water. The E/water subgroup kept up the high level of EtOH intake, while in $\mathrm{E}+\mathrm{D} /$ water subgroup, EtOH intake was greatly reduced to $1.8 \pm 1.0 \mathrm{~g} / \mathrm{kg} / \mathrm{d}$ at the end of the seventh week, and $1.2 \pm 0.2 \mathrm{~g} / \mathrm{kg} / \mathrm{d}$ at the end of the eighth week, similar to that of the group started with $\mathrm{E}+\mathrm{D} /$ water (two-way RM ANOVA, $F_{(2,227)}=169.69, p<0.001$, with significant interaction between treatments and treatment days; $F_{(36,227)}=4.11, p<0.001, \mathrm{E}+\mathrm{D} /$ water group vs $\mathrm{E} /$ water group; $p<0.001, \mathrm{E}+\mathrm{D} /$ water from seventh 
week vs E/water group in weeks 8-10; Fig. $3 A$ ). The $\mathrm{E} /$ water group showed significantly increased preference to bottle containing $\mathrm{EtOH}(n=6-8$ rats per group, twoway RM ANOVA, $F_{(1,31)}=7.06, p=0.019$, with interaction $F_{(1,31)}=16.0, p=0.001$; Figure $3 B$ ), whereas $\mathrm{E}+\mathrm{D} /$ water did not change this preference and drinking remained at the same level as drinking from the bottle containing $\mathrm{E}+\mathrm{D}$. We also noted that, as a control for taste aversion of DHM, there was no significant difference between fluid intake from the bottle of water and from the bottle of DHM ( 50\%) in the $\mathrm{D} /$ water groups. There were no significant differences in total fluid consumption among the four groups. There was no significant difference in body weight among the four groups of rats at the end of the experiments. These results suggest that DHM prevents excessive EtOH consumption and remains effective for a long time (at least 10 weeks) if taken with EtOH. DHM reduces $\mathrm{EtOH}$ consumption when the high voluntary EtOH consumption is already established by exposure to EtOH.

At the end of the sixth week, plasma [EtOH] from $\mathrm{E}+\mathrm{D} /$ water group was significantly lower than that from E/water group ( $n=2$ rats per group; $t$ test; $t=$ 28.3; $\mathrm{df}=1 ; p=0.023$; Fig. $3 C$ ). Plasma $[\mathrm{EtOH}]$ correlated well with the measured amount of EtOH consumed. Plasma [EtOH] (milligram per deciliter) for each animal was measured after 30, 45, 60, and $100 \mathrm{~min}$ of voluntary $20 \% \mathrm{EtOH}$ started on the EtOH day of the end of the sixth week. These data suggest that DHM prevents high voluntary EtOH consumption.

\section{DHM antagonizes EtOH-induced}

$\mathrm{GABA}_{\mathrm{A}} \mathrm{R}$ potentiation, and the effect is blocked by flumazenil

We performed patch-clamp recordings in DGCs from hippocampal slices in vitro. Bath application of EtOH $(60 \mathrm{~mm})$ increased $I_{\text {tonic }}$ from $22.0 \pm 0.7$ to $46.9 \pm 1.4$ pA (one-way RM ANOVA; $F_{(3,31)}=49.92$; $p<0.001$; Fig. $4 A, B)$ and enhanced mIPSCs from $0.53 \pm 0.02$ to $0.64 \pm 0.02 \mathrm{nC}$ ( $n=8$ neurons/3 rats; one-way $\mathrm{RM}$ ANOVA; $F_{(3,34)}=45.24 ; p<0.001$; statistical significance vs drug 0; Fig. $4 A, C$ ), as reported previously (Liang et al., 2007). EtOH effects were concentration-dependently antagonized by DHM (0.3 and $1.0 \mu \mathrm{M}$; Fig. $4 A--C)$. We then tested flumazenil effects on the anti-EtOH actions of DHM. DHM $(3 \mu \mathrm{M})$ decreased EtOH-potentiated $I_{\text {tonic }}$ from $44.8 \pm 2.3$ to $21.0 \pm 0.9 \mathrm{pA}$ and mIPSCs from $0.78 \pm 0.01$ to $0.70 \pm 0.02$ nC. Flumazenil $(10 \mu \mathrm{M})$ reversed the DHM actions on $I_{\text {tonic }}$ (one-way RM
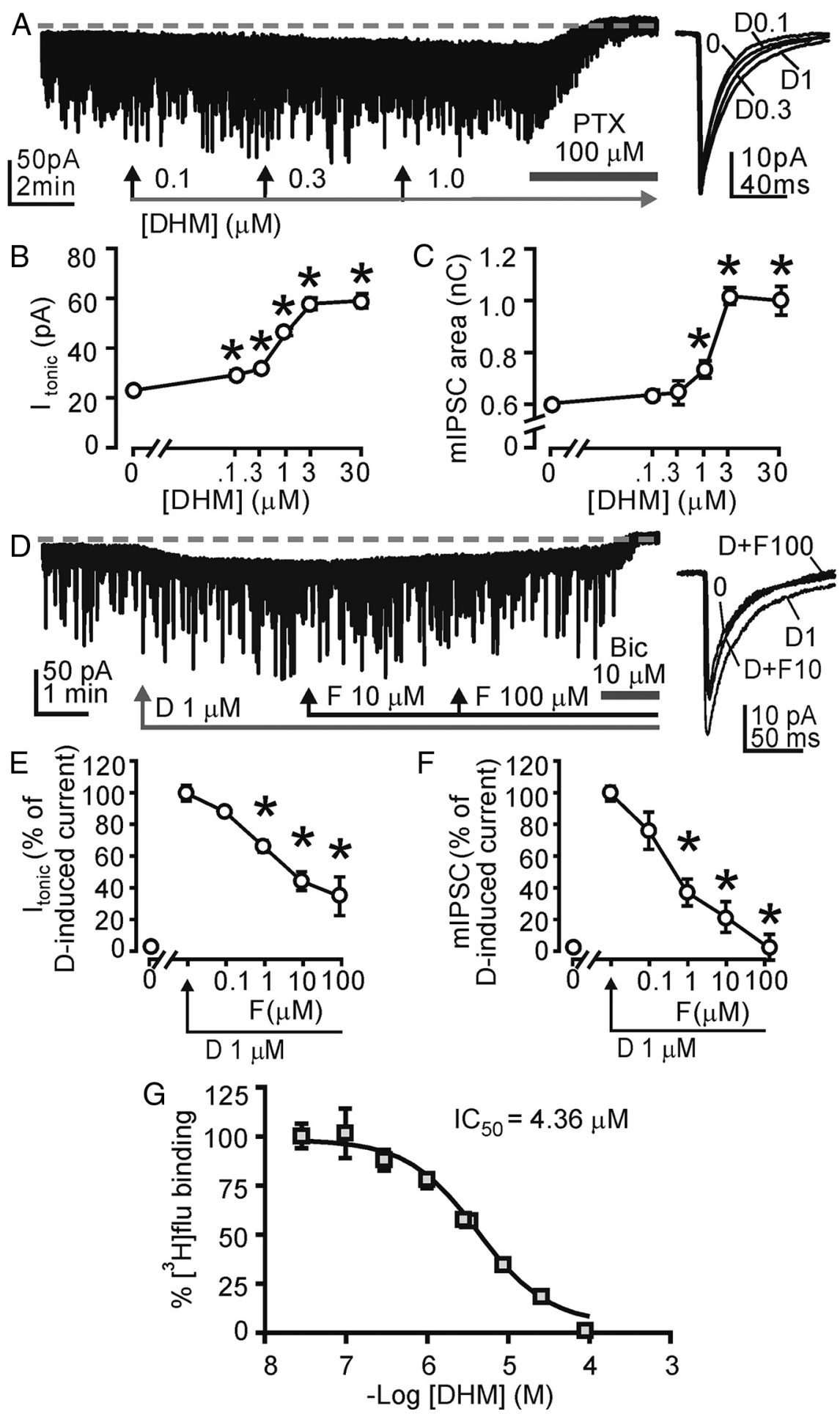

Figure 5. $D H M$ is a positive modulator of $G_{A B A} R s$ at $B Z$ sites. All recordings were whole-cell voltage clamped at -70 $\mathrm{mV}$. $\boldsymbol{A}$, Recording from DGCs (left) in hippocampal slices and superimposed averaged mIPSCs (right). $\boldsymbol{B}, \boldsymbol{C}$, Summary of $I_{\text {tonic }}$ and mIPSC area potentiated by DHM from 0.1 to $30 \mu \mathrm{M}\left(n=8\right.$ neurons/3 rats). ${ }^{*}$ Statistical significance versus drug 0 ( $\boldsymbol{A}$, C). D, Recording from a cultured hippocampal neuron at DIV14. DHM (1 $\mu \mathrm{M}$; D1) enhancement of GABA $\mathrm{R}_{\mathrm{R}}$-mediated $I_{\text {tonic }}$ and mIPSCs were reversed by flumazenil (F; 10 and $100 \mu \mathrm{m})$. All $G_{A B A_{A}} R$ currents were blocked by bicuculline $\left(G_{A B A_{A}} R\right.$ antagonist; Bic; $10 \mu \mathrm{m}$; gray dashed line). $\boldsymbol{E}, \boldsymbol{F}$, Summary (\% of DHM-induced current) of D1 enhancements of $I_{\text {tonic }}$ and mIPSCs, which were inhibited by flumazenil ( $n=8$ neurons/3 rats). $\mathbf{G}$, DHM inhibited [ ${ }^{3} \mathrm{H}$ ]flunitrazepam (flu) binding in rat cortex membrane homogenates. Increasing the final concentrations of DHM (0.03-100 $\mu \mathrm{m})$ results in displacement of $\left[{ }^{3} \mathrm{H}\right]$ flunitrazepam (final concentration of $1 \mathrm{~nm}$ ) at cortical binding sites. Results are graphed by GraphPad Prism 4.0 and presented as the average of two experiments with each point done in triplicate $(n=2)$. ${ }^{*}$ Statistical significance versus flumazenil $0(\boldsymbol{D}-\boldsymbol{F})$. 
Table 2. The effects of DHM on mIPSC kinetics and $I_{\text {tonic }}$ magnitudes in DGCs of naive rats

\begin{tabular}{|c|c|c|c|c|c|c|}
\hline & Frequency (HZ) & mIPSC area (fC) & mIPSC amplitude (pA) & Rise time (ms) & Decay time (ms) & $I_{\text {tonic }}(\mathrm{pA})$ \\
\hline Baseline & $13.8 \pm 0.7$ & $585.2 \pm 14.4$ & $30.5 \pm 2.1$ & $2.0 \pm 0.1$ & $6.7 \pm 0.6$ & $22.5 \pm 2.5$ \\
\hline DHM $0.1 \mu \mathrm{M}$ & $14.0 \pm 0.6$ & $637.1 \pm 19.8^{*}$ & $30.9 \pm 2.9$ & $2.0 \pm 0.2$ & $7.5 \pm 0.5$ & $27.6 \pm 1.4^{*}$ \\
\hline DHM $1 \mu \mathrm{M}$ & $15.0 \pm 0.6$ & $715.7 \pm 26.2^{*}$ & $32.7 \pm 2.6$ & $2.1 \pm 0.2$ & $8.6 \pm 0.5^{*}$ & $44.0 \pm 4.1^{*}$ \\
\hline DHM $10 \mu \mathrm{M}$ & $15.9 \pm 1.0$ & $965.7 \pm 30.9^{*}$ & $36.1 \pm 2.4$ & $2.4 \pm 0.3$ & $9.6 \pm 0.8^{*}$ & $53.8 \pm 2.9^{*}$ \\
\hline DHM $30 \mu \mathrm{M}$ & $16.1 \pm 1.7^{*}$ & $956.7 \pm 22.6^{*}$ & $35.8 \pm 3.0^{*}$ & $2.4 \pm 0.2$ & $10.1 \pm 0.8^{*}$ & $54.0 \pm 3.4^{*}$ \\
\hline
\end{tabular}

Data (mean \pm SEM) were obtained from hippocampal slices. $n=5-7$ neurons from 3 rats.

${ }^{*} p<0.05$ versus baseline (one-way ANOVA).

ANOVA; $F_{(3,18)}=115.81 ; p<0.001$ ) and mIPSCs (one-way RM ANOVA; $F_{(3,19)}=47.48 ; p<0.001$; statistical significance vs drug $0 ; n=5$ neurons $/ 2$ rats; Fig. $4 D-F)$. These data suggest that DHM antagonizes EtOH-induced potentiation of both extrasynaptic and synaptic $\mathrm{GABA}_{\mathrm{A}} \mathrm{Rs}$, and the effects are blocked by flumazenil. These data are consistent with the behavioral experiment observations (Fig. 1C) indicating that interaction of $\mathrm{DHM}$ and $\mathrm{EtOH}$ on $\mathrm{GABA}_{\mathrm{A}} \mathrm{R}$ BZ sites is a cellular mechanism underlying the therapeutic effects of DHM on $\mathrm{EtOH}$ intoxication.

We also tested quercetin, another flavonoid purified from $\mathrm{Ho}-$ venia with a similar chemical structure. Acute EtOH potentiated $I_{\text {tonic }}$ and mIPSCs, while subsequent application of quercetin $(0.3$ and $1 \mu \mathrm{M})$ did not change EtOH-induced potentiation $(n=5$ neurons/2 rats; one-way RM ANOVA; $F_{(3,18)}=43.20 ; p<0.001$; Fig. 4G-I). Post hoc multiple comparison shows no significant change in $I_{\text {tonic }}$ and mIPSCs after initial potentiation by EtOH. These data indicate that the antagonism of DHM of EtOH effects on $\mathrm{GABA}_{\mathrm{A}} \mathrm{Rs}$ is, to some extent, is unique.

\section{DHM is a positive modulator of $\mathrm{GABA}_{\mathrm{A}}$ Rs at the $\mathrm{BZ}$ sites}

We further studied DHM $(0.1$ to $30 \mu \mathrm{M})$ effects on $\mathrm{GABA}_{\mathrm{A}} \mathrm{R}$ mediated $I_{\text {tonic }}$ and mIPSCs of DGCs in hippocampal slices. DHM $(1 \mu \mathrm{M})$ enhanced $I_{\text {tonic }}$ (one-way RM ANOVA; $F_{(5,32)}=$ 78.16; $p<0.001$; Fig. $5 A, B$ ) and increased mIPSC area (one-way RM ANOVA; $F_{(5,34)}=46.80 ; p<0.001$; statistical significance vs drug $0 ; n=8$ neurons/ 3 rats; Fig. $5 A, C$ ) in a concentrationdependent manner ( 0.1 to $30 \mu \mathrm{M})$. We also analyzed DHM effects on mIPSC frequency and kinetics as shown in Table 2. The DHM enhancement of mIPSCs was primarily due to decay time prolongation. These results suggest that DHM potentiates both extrasynaptic and postsynaptic $\mathrm{GABA}_{\mathrm{A}} \mathrm{Rs}$.

To further examine the site of DHM actions on $\mathrm{GABA}_{\mathrm{A}} \mathrm{Rs}$, we tested flumazenil effects on DHM enhancement of $\mathrm{GABA}_{\mathrm{A}} \mathrm{R}$ function in cultured hippocampal neurons at DIV13-DIV14. DHM $(1 \mu \mathrm{M})$ potentiated $I_{\text {tonic }}(194.9 \pm 13.6 \%$ of baseline; Fig. $5 D, E)$ and mIPSC area $(181.8 \pm 9.2 \%$ of baseline; Fig. $5 D, F)$. Flumazenil inhibited the DHM enhancement on $\mathrm{GABA}_{\mathrm{A}} \mathrm{R}$ currents in a concentration-dependent manner ( $I_{\text {tonic }}$, one-way RM ANOVA, $F_{(5,57)}=7.55, p<0.001 ;$ mIPSCs, one-way RM ANOVA, $F_{(5,54)}=10.16, p<0.001$; statistical significance vs flumazenil $0 ; n=8$ neurons/3 rats; Fig. $5 D--F$ ). These observations suggest that DHM acts on the same sites on $\mathrm{GABA}_{\mathrm{A}}$ Rs as BZs.

We then examined DHM $(0.03-100 \mu \mathrm{M})$ actions on BZ sites using $\left[{ }^{3} \mathrm{H}\right]$ flunitrazepam binding in cortical membrane homogenates from naive adult rats. Significant inhibition of $\left[{ }^{3} \mathrm{H}\right]$ flunitrazepam binding by DHM was observed, starting at $0.3 \mu \mathrm{M}$ in a concentration-dependent manner, with an $\mathrm{IC}_{50}$ of $4.36 \mu \mathrm{M}$ and Hill slope of $-0.73(n=2$; Fig. $5 G)$. These data suggest that DHM directly inhibits $\left[{ }^{3} \mathrm{H}\right]$ flunitrazepam binding to $\mathrm{GABA}_{\mathrm{A}} \mathrm{Rs}$, apparently competitively, indicating that DHM likely acts on $\mathrm{GABA}_{\mathrm{A}} \mathrm{R}$ BZ sites.

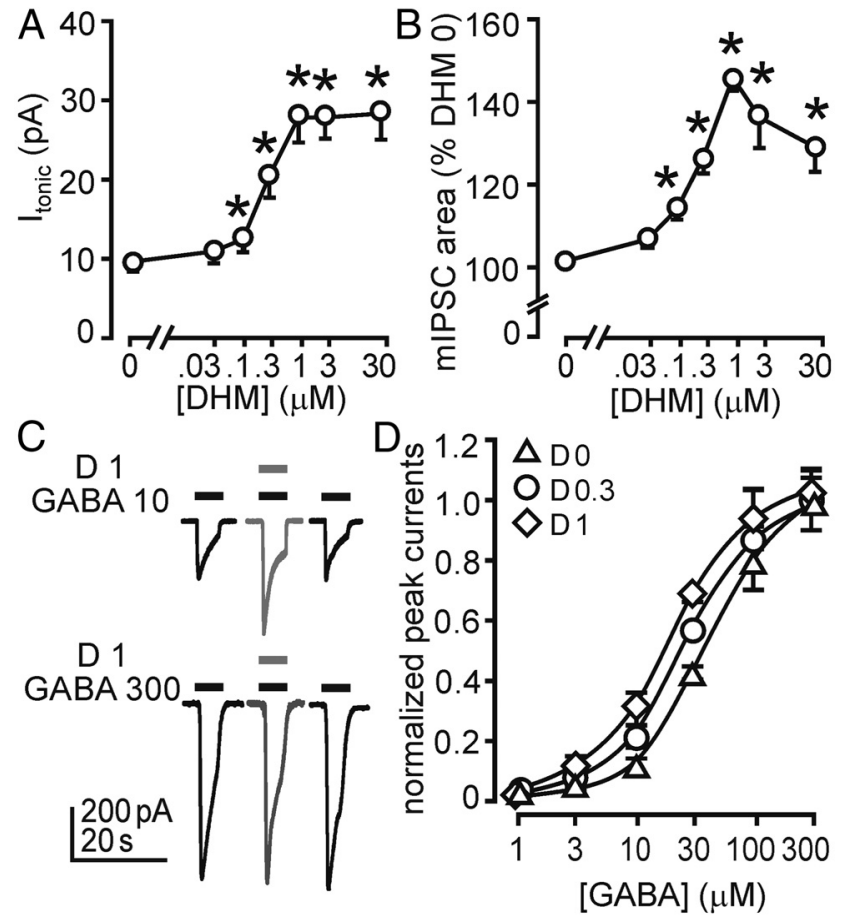

Figure 6. DHM potentiates $G_{A B A_{A}} \mathrm{R}$-mediated inhibition in a concentrationdependent manner in primary cultured hippocampal neurons (DIV14). Neurons were whole-cell voltage clamped at $-70 \mathrm{mV}$. A, B, Dose-response curves of DHM on $I_{\text {tonic }}$ and mIPSCs ( $n=9-10$ neurons). *Statistical significance versus drug 0. C, DHM (1 $\mu \mathrm{m})$ enhanced $G_{A B A}$ R currents evoked by focal puffs of 10 and $300 \mu \mathrm{M} G A B A$. D, The concentration-response curve of $G A B A_{A} R$ currents induced by focal puffs of $G A B A$ was left shifted by DHM ( 0.3 and $1 \mu \mathrm{M})$. Data (mean \pm SEM) were obtained from the average of GABAinduced currents normalized to the peak currents induced by $300 \mu \mathrm{M} G A B A$ in neurons ( $n=6-8$ neurons).

We further examined the concentration dependence of DHM effects on $\mathrm{GABA}_{\mathrm{A}} \mathrm{R}$-mediated currents in cultured hippocampal neurons. DHM concentration-dependently potentiated $I_{\text {tonic }}$ (oneway RM ANOVA; $\left.F_{(6,74)}=26.34 ; p<0.001 ; \mathrm{EC}_{50}, \sim 0.20 \mu \mathrm{M}\right)$ and increased mIPSCs (one-way RM ANOVA; $F_{(5,66)}=28.29 ; p<0.001$; statistical significance vs drug $0 ; n=9-10 ; \mathrm{EC}_{50}, \sim 0.20 \mu \mathrm{M}$; the responses to $>1 \mu \mathrm{M}$ DHM decreased slightly; Fig. $6 A, B)$.

We also tested DHM effects on $\mathrm{GABA}_{\mathrm{A}} \mathrm{R}$ currents induced by focal puffs of 10 and $300 \mu \mathrm{M}$ GABA in the presence of TTX in cultured neurons at DIV14. Coapplication of DHM $(0.3$ and $1 \mu \mathrm{M})$ with GABA increased peak GABA currents and produced a left shift of the GABA concentration-response curve $(n=6-8$; Fig. $6 C, D)$. These results suggest that $\mathrm{DHM}$ acts on $\mathrm{GABA}_{\mathrm{A}}$ Rs directly and potently potentiates extrasynaptic and/or postsynaptic $\mathrm{GABA}_{\mathrm{A}} \mathrm{Rs}$.

DHM prevents EtOH exposure/withdrawal-induced $\mathrm{GABA}_{\mathrm{A}} \mathrm{R}$ plasticity in rat hippocampus

We examined the total protein content of the $\mathrm{GABA}_{\mathrm{A}} \mathrm{R} \alpha 4$ subunit in rat hippocampus $48 \mathrm{~h}$ after withdrawal from vehicle (V/ 
W), EtOH ( $3 \mathrm{~g} / \mathrm{kg}$; E/W), EtOH combined with DHM (1 mg/kg, E+D/W), and DHM (D/W) treatments (intraperitoneal injection, the same as mentioned in Fig. 2). Western blots showed that EtOH exposure increased the total $\alpha 4$ protein level to $184.0 \pm 26.0 \%$ compared to the $\mathrm{V} / \mathrm{W}$ group; this increase was blocked in the $\mathrm{E}+\mathrm{D} / \mathrm{W}$ group $(93.0 \pm 21.0 \%$ of control; significant difference vs V/W group). Two-way ANOVA analysis revealed a significant DHM effect by EtOH exposure/ withdrawal interaction on the total $\alpha 4$ protein level $\left(F_{(1,15)}=8.93 ; p=0.011\right.$; $n=3$ /group; Fig. $7 A, B)$. DHM exposure had no effect on $\alpha 4$ subunit level. These data indicate that DHM prevents $\mathrm{EtOH}$ exposure/withdrawal-induced $\mathrm{GABA}_{\mathrm{A}} \mathrm{R}$ plasticity in vivo.

We demonstrated previously that $\mathrm{EtOH}$ exposure/withdrawal produces profound $\mathrm{GABA}_{\mathrm{A}} \mathrm{R}$ plasticity, which manifests as a switch in the EtOH sensitivity from extrasynaptic to synaptic $\mathrm{GABA}_{\mathrm{A}} \mathrm{R}$-mediated currents (Liang et al., 2007; Shen et al., 2011), which could be a mechanism underlying EtOH withdrawal signs. Here, we tested whether DHM prevents $\mathrm{EtOH}$-induced $\mathrm{GABA}_{\mathrm{A}} \mathrm{R}$ plasticity in CNS neurons.

Four groups of rats were gavaged with vehicle (V/W), EtOH (5 g/kg; E/W), EtOH combined with DHM $(1 \mathrm{mg} / \mathrm{kg} ; \mathrm{E}+\mathrm{D} /$ $\mathrm{W})$, or DHM $(\mathrm{D} / \mathrm{W})$. W represents $48 \mathrm{~h}$ withdrawal. Then whole-cell $\mathrm{GABA}_{\mathrm{A}} \mathrm{R}$ mediated currents were recorded on DGCs in hippocampal slices of rats after $48 \mathrm{~h}$ withdrawal from the four treatments, respectively. In the V/W group, bath application of EtOH $(60 \mathrm{~mm})$ enhanced $I_{\text {tonic }}$ from $28.8 \pm$ 3.1 to $62.1 \pm 3.3 \mathrm{pA}$ ( $n=4-7$ neurons per group; two-way RM ANOVA, $F_{(3,29)}=$ 48.45, $p<0.001$; with DHM effects by $\mathrm{EtOH}$ exposure/withdrawal interaction, $F_{(3,29)}=39.21, p<0.001$; Fig. $\left.8 A, E\right)$. It enhanced mIPSC area from $0.67 \pm 0.06$ to $0.78 \pm 0.05 \mathrm{nC}(n=4-7$ neurons per group, two-way RM ANOVA, $F_{(3,29)}=$ $6.98, p=0.007$; with DHM effects by EtOH exposure/withdrawal interaction, $F_{(3,29)}=12.15, p<0.001$; significant difference between $60 \mathrm{~mm}$ and $0 \mathrm{EtOH}$, and significant difference vs the $\mathrm{V} / \mathrm{W}$ group; Fig. $8 A, F)$. In the $\mathrm{E} / \mathrm{W}$ group, $\mathrm{EtOH}$ did not increase $I_{\text {tonic }}$ (Fig. $8 B, E$ ), while greatly enhancing mIPSC area from $0.70 \pm 0.03$ to $1.4 \pm 0.04 \mathrm{nC}$ (Fig. $8 B, F$ ). In the $\mathrm{E}+\mathrm{D} / \mathrm{W}$ group, $\mathrm{EtOH}$ increased $I_{\text {tonic }}$ from $30.0 \pm 2.8$ to $60.0 \pm 2.2 \mathrm{pA}$ (Fig. $8 C, E$ ), while mIPSC modulation was unchanged (Fig. $8 C, F$ ). In the D/W group, the responses of $I_{\text {tonic }}$ and mIPSCs to $\mathrm{EtOH}$ were similar to those of the V/W group (Fig. 8D,E). The baseline mIPSC frequency and kinetics as well as $I_{\text {tonic }}$ magnitudes from DGCs of the four groups of rats are shown in Table 3 . These results suggest that intragastric $\mathrm{EtOH}$ with DHM prevents both the subsequent tolerance to $\mathrm{EtOH}$ and $\mathrm{EtOH}$-induced $\mathrm{GABA}_{\mathrm{A}} \mathrm{R}$ plasticity. Interestingly, DHM acts equally well orally (gavage) or by intraperitoneal injection.
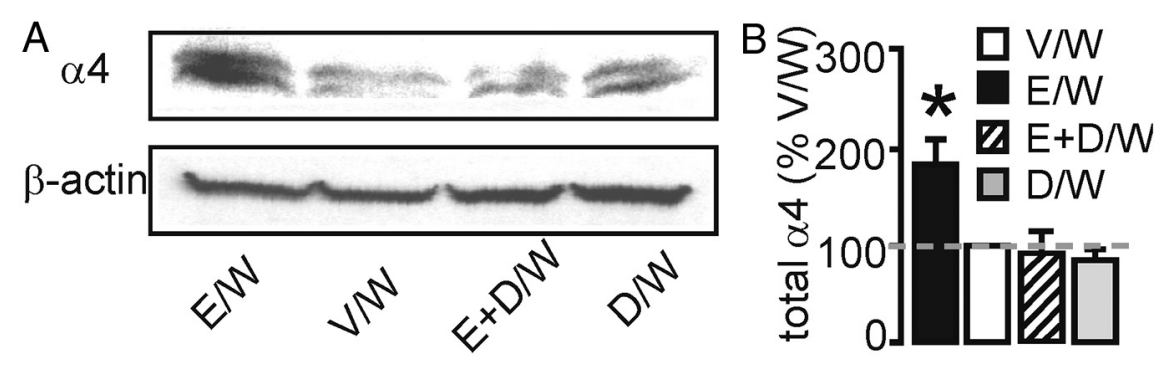

Figure 7. DHM prevents EtOH exposure/withdrawal-induced alteration in $\mathrm{GABA}_{A} \mathrm{R} \alpha 4$ subunit expression in rat hippocampus Four groups of rats were injected (intraperitoneally) with single-dose vehicle (V/W), EtOH ( $3 \mathrm{~g} / \mathrm{kg}$; E/W), EtOH plus DHM (1 mg/kg; wehicle, EtOH,E+D, or DHM. $\beta$-actin is shown as a loading control. B, Ouantification of total $\alpha 4$ subunit protein from A. EtOH-withdrawal induced an increase in $\alpha 4 \mathrm{GABA}_{\mathrm{A}} \mathrm{R}$ subunit, whereas $\mathrm{E}+\mathrm{D} / \mathrm{W}$ treatment prevented this increase. DHM did not
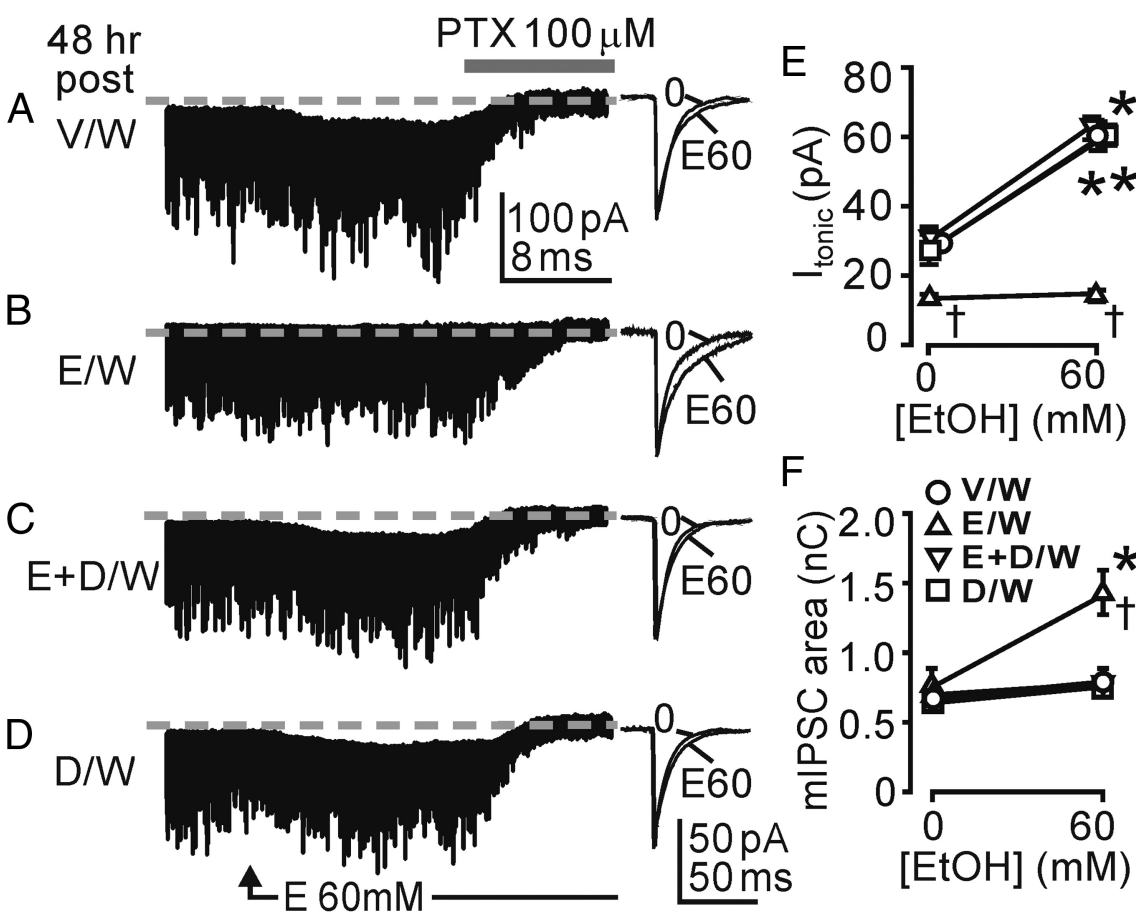

Figure 8. DHM prevents EtOH exposure/withdrawal-induced $G_{A B} A_{A} R$ plasticity. Rats were divided into four groups and gavaged with vehicle (V/W), EtOH (5 g/kg; E/W), EtOH combined with DHM (1 mg/kg; E+D/W) or DHM (D/W). Then whole-cell patch-clamp recordings at $-70 \mathrm{mV}$ were performed on DGCs in hippocampal slices. $A$, Acute EtOH $(60 \mathrm{~mm})$ enhanced $I_{\text {tonic }}$ and mIPSCs in vehicle-treated rats. $\boldsymbol{B}$, In the E/W group, EtOH did not increase $I_{\text {tonic }}$, but greatly enhanced $\mathrm{mIPSC}$ area. $\boldsymbol{C}$, In the E+D/W D/W group were similar to those of the V/W group. $E, F$, Summary of EtOH effects on $I_{\text {tonic }}$ and mIPSCs in the four groups $(n=4-7$ neurons per group). ${ }^{*}$ Significant difference between $60 \mathrm{~mm}$ and $0 \mathrm{EtOH}$; ${ }^{\top}$ significant difference versus the $\mathrm{V} / \mathrm{W}$ group.

We also tested DHM effects on cultured neurons pre-exposed to $\mathrm{EtOH}$. Twenty-four hours after withdrawal from $\mathrm{EtOH}$ exposure, bath application of DHM enhanced $I_{\text {tonic }}$ and mIPSCs concentration dependently $\left(0.03-30 \mu \mathrm{M} ; I_{\text {tonic }}\right.$, one-way RM ANOVA, $F_{(6,35)}=$ $79.90, p<0.001$; mIPSCs, one-way RM ANOVA, $F_{(5,38)}=11.75$, $p<0.001$; significant difference vs drug $0 ; n=8-9$ neurons per group; Fig. $9 A, B)$. The $\mathrm{EC}_{50}$ values enhancing $I_{\text {tonic }}(\sim 0.20 \mu \mathrm{M})$ and mIPSCs $(\sim 0.15 \mu \mathrm{M})$ were similar to those in control neurons without pre-exposure to EtOH (Fig. 6 A,B). The data suggest that DHM remains effective in potentiating extrasynaptic and/or postsynaptic $\mathrm{GABA}_{\mathrm{A}} \mathrm{Rs}$ even following EtOH exposure that leads to tolerance to $\mathrm{EtOH}$.

We measured the surface expression of the $\alpha 4$ subunit in cultured neurons using cell-surface biotinylation followed by West- 
Table 3. Baseline mIPSC kinetics and $\mathrm{I}_{\text {tonic }}$ in DGCs from rats after vehicle, EtOH, EtOH + DHM, or DHM exposure/withdrawal

\begin{tabular}{|c|c|c|c|c|c|c|}
\hline & Frequency $(\mathrm{Hz})$ & mIPSC area (fC) & mIPSC amplitude (pA) & Rise time (ms) & Decay time (ms) & $I_{\text {tonic }}(\mathrm{pA})$ \\
\hline V/W & $12.2 \pm 1.7$ & $674.9 \pm 60.7$ & $32.6 \pm 2.3$ & $2.0 \pm 0.2$ & $6.9 \pm 0.6$ & $28.8 \pm 3.1$ \\
\hline$E / W$ & $11.4 \pm 0.8$ & $698.0 \pm 33.7$ & $38.3 \pm 3.3$ & $0.8 \pm 0.3$ & $4.0 \pm 0.4$ & $13.0 \pm 1.0$ \\
\hline$E+D / W$ & $12.4 \pm 0.5$ & $666.8 \pm 34.1$ & $26.2 \pm 2.1$ & $1.8 \pm 0.3$ & $7.1 \pm 0.6$ & $30.0 \pm 2.8$ \\
\hline $\mathrm{D} / \mathrm{W}$ & $13.2 \pm 1.3$ & $621.5 \pm 68.5$ & $28.5 \pm 3.0$ & $2.2 \pm 0.3$ & $7.9 \pm 1.2$ & $24.3 \pm 2.9$ \\
\hline
\end{tabular}

Data (mean \pm SEM) were obtained from hippocampus slice from rats $48 \mathrm{~h}$ after vehicle, EtOH, $\mathrm{E}+\mathrm{D}$, and DHM administration (gavage). $n=7-8$ neurons from 3 rats.
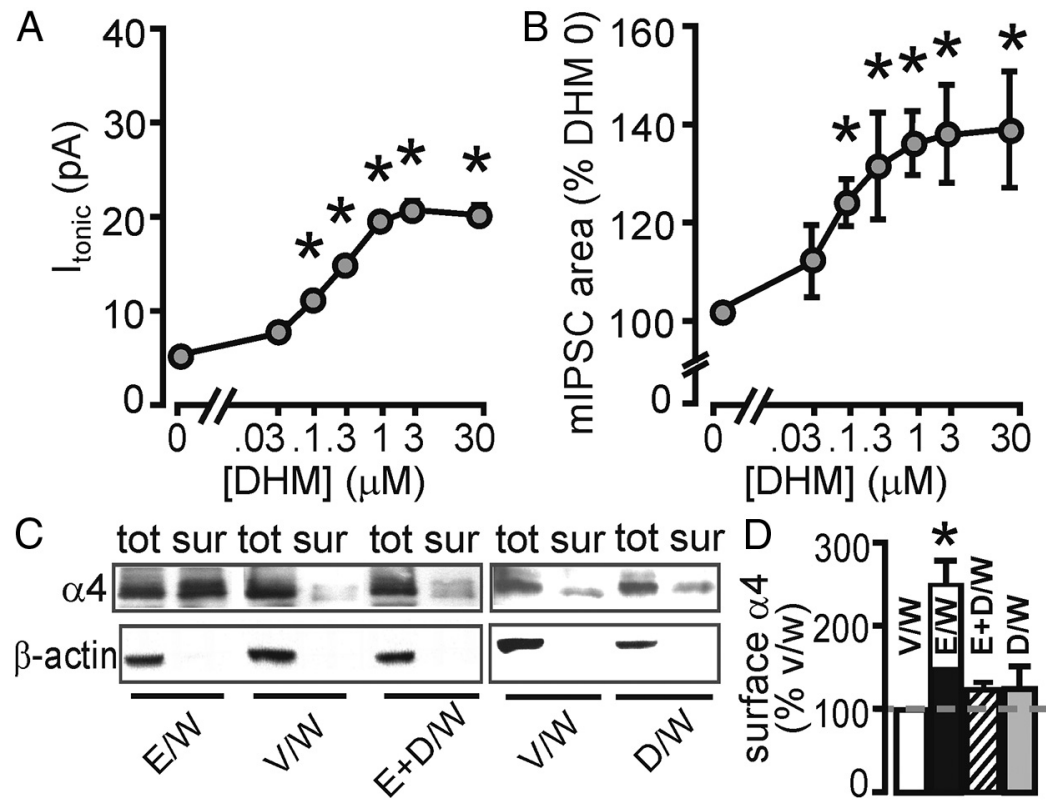

Figure 9. DHM potentiates $\mathrm{GABA}_{A} \mathrm{R}$-mediated inhibition in EtOH pre-exposed cultured neurons. Coadministration of DHM with EtOH prevents Et0H exposure/removal-induced $\mathrm{GABA}_{A} \mathrm{R}$ plasticity in vitro. $\boldsymbol{A}, \boldsymbol{B}$, In cultured hippocampal neurons (DIV13-DIV14) $24 \mathrm{~h}$ after Et0H exposure $(60 \mathrm{~mm}, 30 \mathrm{~min})$, DHM still enhanced both $\mathrm{GABA}_{\mathrm{A}} \mathrm{R}$-mediated $I_{\text {tonic }}(\boldsymbol{A})$ and $\mathrm{mIPSC}$ area $(\boldsymbol{B})$ concentration dependently without tolerance (compare Fig. $6 A, B ; n=8-9$ neurons per group). * Significant difference versus drug 0 ( $n=8-9$ neurons per group). $C$, Coadministration of EtOH with DHM prevents EtOH exposure/removal-induced $\mathrm{GABA}_{\mathrm{A}} \mathrm{R}$ plasticity. Representative Western blot shows cell-surface expression (sur) versus total (tot) expression of $G_{A B} A_{A} R \alpha 4$ subunit in cultured hippocampal neurons (DIV13-DIV14) detected $24 \mathrm{~h}$ after the four treatments of V/W, E/W, $\mathrm{E}+\mathrm{D} / \mathrm{W}$, or D/W, respectively. $\beta$-Actin is shown as a loading control and was not detectable on cell surfaces. $\boldsymbol{D}$, Quantification of surface $\mathrm{GABA}_{\mathrm{A}} \mathrm{R} \alpha 4$ protein (\% V/W). Surface signal was normalized to the respective $\beta$-actin signal (vehicle, 100\%). EtOH induced a 1.5-fold increase in surface expression of $\mathrm{GABA}_{\mathrm{A}} \mathrm{R} \alpha 4$ protein, while $\mathrm{E}+\mathrm{D}$ prevented this increase ( $n=5 /$ group). *Significant difference versus the V/W group.

ern blot analysis. EtOH pre-exposed neurons showed increased $\alpha 4$ subunit surface expression (significant difference vs the $\mathrm{V} / \mathrm{W}$ group); while in neurons pre-exposed to EtOH plus DHM, this increase was blocked (two-way ANOVA analysis revealed a significant DHM effect by EtOH exposure/withdrawal interaction on the total $\alpha 4$ subunit surface expression; $F_{(1,15)}=29.71 ; p<0.001$; Fig. $9 C, D)$. DHM did not alter $\alpha 4$ surface expression. These data indicate that co-administration of $\mathrm{EtOH}$ with DHM prevents $\mathrm{EtOH}$ exposure/removal-induced $\mathrm{GABA}_{\mathrm{A}} \mathrm{R}$ plasticity in vitro.

\section{Discussion}

DHM is a flavonoid compound first found in Hovenia dulcis, in the plant Ampelopsis grossedentata, and in teas (Li et al., 2003); few of its pharmacological properties have been examined. In this study, we found that (1) DHM potently $(1 \mathrm{mg} / \mathrm{kg})$ counteracts acute EtOH intoxication, (2) the counteracting effects are antagonized by the general BZ antagonist flumazenil in vivo, and (3) DHM ameliorates $\mathrm{EtOH}$ exposure/withdrawal-induced behavioral changes, including tolerance to $\mathrm{EtOH}$, increase in basal anxiety, and hypersensitivity to PTZ-induced seizures (hyperexcitability). At the same doses, (4) DHM does not cause intoxication, sedation, anesthesia, nor hyperexcitability, and (5) DHM prevents the escalation of alcohol consumption in an intermittent voluntary alcohol intake paradigm in rats. DHM reduces alcohol consumption in rats that drink high levels of alcohol following intermittent alcohol exposure; yet, at the cellular level in CNS neurons (in slices and cultured neurons), (6) DHM antagonizes acute $\mathrm{EtOH}$-induced potentiation of $\mathrm{GABA}_{\mathrm{A}} \mathrm{Rs}$, (7) DHM antagonizes EtOH exposure/removal-induced alterations in responsiveness of $\mathrm{GABA}_{\mathrm{A}} \mathrm{Rs}$ to acute EtOH including loss of $I_{\text {tonic }}$ modulation and increased mIPSC sensitivity, (8) DHM potentiates $\mathrm{GABA}_{\mathrm{A}} \mathrm{Rs}$ in hippocampal slices and cultured neurons and retains efficacy in potentiating $\mathrm{GABA}_{\mathrm{A}} \mathrm{Rs}$ even after EtOH exposure/withdrawal, which induces tolerance to $\mathrm{EtOH}$, (9) DHM effects on $\mathrm{GABA}_{\mathrm{A}} \mathrm{Rs}$ are inhibited by flumazenil in vitro, (10) DHM competitively inhibits BZ site $\left[{ }^{3} \mathrm{H}\right]$ flunitrazepam binding in rat cortical membrane homogenates, (11) DHM blocks EtOH exposure/ withdrawal-induced increases in the amount of $\mathrm{GABA}_{\mathrm{A}} \mathrm{R} \alpha 4$ subunits in rat hippocampus, and (12) DHM blocks $\mathrm{EtOH}$ pre-exposure-induced increase in $\alpha 4$ subunit surface expression in culture hippocampal neurons. In summary, we determined the effects of DHM on EtOH actions in animal models, a major molecular target of DHM for counteracting $\mathrm{EtOH}$ intoxication and dependence, as well as its underlying cellular mechanisms.

DHM counteracts acute EtOH intoxication and ameliorates AWS by acting on $\mathrm{GABA}_{\mathrm{A}} \mathrm{Rs}$

We and others (Valenzuela, 1997; Cagetti et al., 2003; Liang et al., 2006, 2007; Kumar et al., 2009; Heilig et al., 2010) have shown that acute and chronic EtOH administration produce $\mathrm{GABA}_{\mathrm{A}} \mathrm{R}$ plasticity in rats that contribute to altered behaviors in AWS and alcohol dependence. We identified DHM by screening herbal medicines used for alcohol disorders for the ability to ameliorate EtOH-induced $\mathrm{GABA}_{\mathrm{A}} \mathrm{R}$ plasticity and found that DHM not only had that action but also was effective in blocking acute EtOH intoxication, and withdrawal, as well as accelerated EtOH voluntary consumption. Our findings are consistent with current theories linking acute and chronic effects of EtOH with $\mathrm{GABA}_{\mathrm{A}} \mathrm{Rs}$ and suggest strongly that DHM blocking EtOH's effect involves $\mathrm{GABA}_{\mathrm{A}}$ Rs, especially in light of flumazenil's block of all DHM effects in vivo and on $\mathrm{GABA}_{\mathrm{A}} \mathrm{R}$-mediated current in vitro. 


\section{Current medications for EtOH intoxication and AUD}

BZs are classical medications for reducing symptoms of AWS, and they act on $\mathrm{GABA}_{\mathrm{A}}$ Rs. However, BZs (e.g., diazepam) exhibit cross-tolerance in behavioral depression and $\mathrm{GABA}_{\mathrm{A}} \mathrm{R}$ enhancement after EtOH treatment (Devaud et al., 1996). Yet, frequent use of BZs can lead to dependence. Therefore, although BZs can treat life-threatening AWS, developing dual addictions makes BZs unsuitable for alcohol abuse therapy.

Besides BZs, only three medications (oral naltrexone, acamprosate, and disulfiram) are currently approved for treating alcohol dependence by the U.S. Food and Drug Administration. All of these medications aim to treat relapse to heavy drinking; however, all have limited success. In all of these cases, the receptors for alcohol actions are not directly affected, or even targeted, nor are the underlying mechanisms of interaction with alcohol clarified (except for disulfiram, which blocks acetaldehyde metabolism). Considering the heterogeneous nature of alcohol use disorders, many patients have limited or no response to these medications. Other candidate targets are under study but so far lack convincing evidence for success (Hester and Miller, 2003; O'Malley et al., 2003; Heilig and Egli, 2006; Johnson, 2010).

Kudzu is the only Eastern medication mentioned by the NIAAA (http://grants1.nih.gov/grants/guide/pa-files/PA-10-100. html). Possible treatment of alcohol craving and reduced EtOH drinking by animals and human heavy drinkers were reported for kudzu extract (Keung and Vallee, 1993; Lukas et al., 2005) due to some isoflavone ingredients, like daidzein, puerarin, and genistein (Johnson, 2010), mimicked by a synthetic analog CVT10216 (Arolfo et al., 2009). Kudzu's mechanism of action was suggested to reduce blood EtOH levels involving mitochondrial acetaldehyde dehydrogenase ALDH2 and/or gastric emptying effects. Reduction of EtOH-induced LORR by daidzin was observed for EtOH administered gastrically but not intraperitoneally ( $\mathrm{Lin}$ and $\mathrm{Li}, 1998$ ), consistent with delayed stomach emptying.

\section{DHM effects beyond EtOH pharmacokinetics}

It has been reported that Hovenia relieves hangover by decreasing blood EtOH concentrations, promoting alcohol clearance, and enhancing the alcohol metabolic enzymes, ADH and ALDH (Kim et al., 2000; Chen et al., 2006). In this study, we showed that DHM, like other flavonoids, has a relatively weak ability to reduce the rate of rise of blood alcohol concentration. However, this cannot account for the actions of DHM on blocking EtOH effects in vivo, since when we decreased the doses of DHM to 0.3 and $0.5 \mathrm{mg} / \mathrm{kg}$, DHM apparently did not affect EtOH pharmacokinetics while still strongly counteracting EtOH-induced LORR (Fig. $1 B$ ), suggesting potency of DHM. When we increased the dose of EtOH ( $4 \mathrm{~g} / \mathrm{kg}), 1 \mathrm{mg} / \mathrm{kg}$ DHM did not have a significant effect on the magnitude nor the time course of plasma [EtOH] $(\mathrm{Ta}-$ ble 1), but greatly reduced the EtOH-induced LORR. In this study, we demonstrated a likely more important mechanism. DHM has direct effects on $\mathrm{GABA}_{\mathrm{A}} \mathrm{Rs}$, the major targets of $\mathrm{EtOH}$ that contribute to AWS and EtOH dependence. More importantly, the DHM effects on EtOH intoxication and $\mathrm{GABA}_{\mathrm{A}} \mathrm{R}$ plasticity can be reversed by flumazenil in vivo (Fig. 1 ) and in vitro (Figs. 4,5 ). These results indicate that DHM has complex interactions with $\mathrm{GABA}_{\mathrm{A}} \mathrm{Rs}$ that counteract $\mathrm{EtOH}$ effects. DHM potentiates $\mathrm{GABA}_{\mathrm{A}}$ Rs in CNS neurons and retains efficacy in potentiating $\mathrm{GABA}_{\mathrm{A}}$ Rs even after EtOH exposure/withdrawal, which induces tolerance to EtOH (Figs. 6, 9); thus, it may be an effective pharmacotherapy for patients who are tolerant to other medications for alcoholism and AWS such as BZs.

\section{DHM compared with other BZ ligands: preliminary observations suggest novel pharmacology}

There is some evidence that selected BZ ligands may block some EtOH actions (Suzdak et al., 1986; Koob, 2004; Hanchar et al., 2005; Paul, 2006; Wallner et al., 2006; Lovinger and Homanics, 2007), but this has not resulted in any therapeutic agents. Notably, the imidazobenzodiazepine Ro15-4513 was reported ( $\mathrm{Su}$ zdak et al., 1986; Paul, 2006) to specifically block EtOH behavioral effects in vivo but not other GABAergic sedatives like pentobarbital; Ro15-4513, but not other inverse agonists, was able to inhibit EtOH enhancement of $\mathrm{GABA}_{\mathrm{A}} \mathrm{R}$ function in vitro (Suzdak et al., 1986). More recent data show that Ro15-4513 and selected analogues that are also able to block alcohol behavioral effects can antagonize the EtOH enhancement of extrasynaptic $\delta$ subunit-containing subtypes of $\mathrm{GABA}_{\mathrm{A}}$ Rs (Wallner et al., 2006, 2008). However, although DHM also is able to block EtOH effects and is a $\mathrm{GABA}_{\mathrm{A}} \mathrm{R}$ ligand, DHM and Ro15-4513 are very different, both chemically and pharmacologically. Ro15-4513 has proconvulsant and anxiogenic effects and inhibits most $\mathrm{GABA}_{\mathrm{A}} \mathrm{R}$ subtypes (Paul, 2006). On the contrary, DHM potentiates $\mathrm{GABA}_{\mathrm{A}} \mathrm{R}$-mediated synaptic and especially extrasynaptic tonic currents (Figs. $5 A-C, 6 A, B$ ) and antagonizes EtOH potentiation of $\mathrm{GABA}_{\mathrm{A}}$ Rs. DHM is a positive modulator of $\mathrm{GABA}_{\mathrm{A}}$ Rs acting on the benzodiazepine site potentiating both extrasynaptic and postsynaptic $\mathrm{GABA}_{\mathrm{A}}$ Rs (Fig. $5 A-C$ ), but appears to differ also from "traditional" BZs like diazepam. It is not anxiolytic or sedative at the dose $(1 \mathrm{mg} / \mathrm{kg})$ that blocks EtOH effects. It induces short-time LORR only when doses hundreds-fold higher than its pharmacological dose are applied (Table 1). It will be interesting to study other possible pharmacological actions of DHM consistent with a positive modulation of $\mathrm{GABA}_{\mathrm{A}} \mathrm{Rs}$, as well as the possible subunit selectivity. Such information may be helpful in understanding how DHM interacts with $\mathrm{EtOH}$ in vivo. DHM prevents the escalation of EtOH consumption and remains effective for a long period of time in a chronic intermittent voluntary EtOH intake paradigm. The underlying mechanisms might be related to DHM preventing EtOH-induced $\mathrm{GABA}_{\mathrm{A}} \mathrm{R}$ dysfunction/plasticity by multiple withdrawals from EtOH (Figs. 7, 8). In other words, alcohol craving induced by the hyperexcitable state of AWS is ameliorated by DHM coadministered with EtOH, which reduces initial responses and thus AWS to EtOH. Yet, DHM greatly reduces EtOH consumption when the high voluntary EtOH consumption is already established by exposure to EtOH (Fig. 3). DHM applied even 1 half hour before EtOH administration counteracts EtOH intoxication as effectively as if DHM is concurrently applied with EtOH (Fig. 1D). Therefore, DHM is a realistic, unique candidate for development as a medication for AUDs.

\section{References}

Aguayo LG, Peoples RW, Yeh HH, Yevenes GE (2002) GABA receptors as molecular sites of ethanol action. Direct or indirect actions? Curr Top Med Chem 2:869-885.

Arolfo MP, Overstreet DH, Yao L, Fan P, Lawrence AJ, Tao G, Keung WM, Vallee BL, Olive MF, Gass JT, Rubin E, Anni H, Hodge CW, Besheer J, Zablocki J, Leung K, Blackburn BK, Lange LG, Diamond I (2009) Suppression of heavy drinking and alcohol seeking by a selective ALDH-2 inhibitor. Alcohol Clin Exp Res 33:1935-1944.

Boehm SL, 2nd, Ponomarev I, Jennings AW, Whiting PJ, Rosahl TW, Garrett EM, Blednov YA, Harris RA (2004) $\gamma$-Aminobutyric acid A receptor subunit mutant mice: new perspectives on alcohol actions. Biochem Pharmacol 68:1581-1602. 
Cagetti E, Liang J, Spigelman I, Olsen RW (2003) Withdrawal from chronic intermittent ethanol treatment changes subunit composition, reduces synaptic function, and decreases behavioral responses to positive allosteric modulators of $\mathrm{GABA}_{\mathrm{A}}$ receptors. Mol Pharmacol 63:53-64.

Chen SH, Zhong GS, Li AL, Li SH, Wu LK (2006) Influence of Hovenia dulcis on alcohol concentration in blood and activity of alcohol dehydrogenase (ADH) of animals after drinking. Zhongguo Zhong Yao Za Zhi 31:1094-1096.

Devaud LL, Purdy RH, Finn DA, Morrow AL (1996) Sensitization of gamma-aminobutyric acid A receptors to neuroactive steroids in rats during ethanol withdrawal. J Pharmacol Exp Ther 278:510-517.

Devaud LL, Fritschy JM, Sieghart W, Morrow AL (1997) Bidirectional alterations of $\mathrm{GABA}_{\mathrm{A}}$ receptor subunit peptide levels in rat cortex during chronic ethanol consumption and withdrawal. J Neurochem 69:126-130.

Du J, He D, Sun LN, Han T, Zhang H, Qin LP, Rahman K (2010) Semen Hoveniae extract protects against acute alcohol-induced liver injury in mice. Pharm Biol 48:953-958.

Hanchar HJ, Dodson PD, Olsen RW, Otis TS, Wallner M (2005) Alcoholinduced motor impairment caused by increased extrasynaptic $\mathrm{GABA}_{\mathrm{A}}$ receptor activity. Nat Neurosci 8:339-345.

Heilig M, Egli M (2006) Pharmacological treatment of alcohol dependence: target symptoms and target mechanisms. Pharmacol Ther 111:855-876.

Heilig M, Egli M, Crabbe JC, Becker HC (2010) Acute withdrawal, protracted abstinence and negative affect in alcoholism: are they linked? Addict Biol 15:169-184.

Hester R, Miller W (2003) Treatment approaches: effective alternatives. Needham Heights, MA: Allyn and Bacon.

Hobbs WR, Rall TW, Verdoorn TA (1996) Hypnotics and sedatives; ethanol. In: The pharmacological basis of therapeutics, 9th ed (Hardman JG, Limbird LE, Molinoff PB, et al., eds.), pp 361-396. New York: McGraw-Hill.

Hunkeler W, Mohler H, Pieri L, Polc P, Bonetti EP, Cumin R, Schaffner R, Haefely W (1981) Selective antagonists of benzodiazepines. Nature 290:514-516.

Johnson BA (2010) Medication treatment of different types of alcoholism. Am J Psychiatry 167:630-639.

Keung WM, Vallee BL (1993) Daidzin: a potent, selective inhibitor of human mitochondrial aldehyde dehydrogenase. Proc Natl Acad Sci U S A 90:1247-1251.

Kim KH, Chung YT, Lee JH, Park YS, Shin MK, Kim HS, Kim DH, Lee HY (2000) Hepatic detoxification activity and reduction of serum alcohol concentration of Hovenia dulcis Thunb from Korea and China. Korean J Med Crop Sci 8:225-233.

Koob GF (2004) A role for GABA mechanisms in the motivational effects of alcohol. Biochem Pharmacol 68:1515-1525.

Kumar S, Porcu P, Werner DF, Matthews DB, Diaz-Granados JL, Helfand RS, Morrow AL (2009) The role of $\mathrm{GABA}_{\mathrm{A}}$ receptors in the acute and chronic effects of ethanol: a decade of progress. Psychopharmacology (Berl) 205:529-564.

Li GD, Chiara DC, Cohen JB, Olsen RW (2010) Numerous classes of general anesthetics inhibit etomidate binding to gamma-aminobutyric acid type A $\left(\mathrm{GABA}_{\mathrm{A}}\right)$ receptors. J Biol Chem 285:8615-8620.

Li J, Cheng Y, Bian W, Liu X, Zhang C, Ye JH (2010) Region-specific induction of FosB $/ \Delta$ FosB by voluntary alcohol intake: effects of naltrexone. Alcohol Clin Exp Res 34:1742-1750.

Li S (1590) Compendium of Materia Medica.

Li YQ, Yu ZG, Lu WC (2003) Dihydromyricetin and myricetin content in Ampelopsis grossedentata measured with HPLC technique. Chin. Tradit Herb Drugs 34:1098.

Liang J, Cagetti E, Olsen RW, Spigelman I (2004) Altered pharmacology of synaptic and extrasynaptic $\mathrm{GABA}_{\mathrm{A}}$ receptors on CA1 hippocampal neurons is consistent with subunit changes in a model of alcohol withdrawal and dependence. J Pharmacol Exp Ther 310:1234-1245.

Liang J, Zhang N, Cagetti E, Houser CR, Olsen RW, Spigelman I (2006) Chronic intermittent ethanol-induced switch of ethanol actions from extrasynaptic to synaptic hippocampal $\mathrm{GABA}_{\mathrm{A}}$ receptors. J Neurosci 26:1749-1758.

Liang J, Suryanarayanan A, Abriam A, Snyder B, Olsen RW, Spigelman I (2007) Mechanisms of reversible $\mathrm{GABA}_{\mathrm{A}}$ receptor plasticity after ethanol intoxication. J Neurosci 27:12367-12377.

Liang J, Spigelman I, Olsen RW (2009) Tolerance to sedative/hypnotic ac- tions of GABAergic drugs correlates with tolerance to potentiation of extrasynaptic tonic currents of alcohol-dependent rats. J Neurophysiol 102:224-233.

Lin RC, Li TK (1998) Effects of isoflavones on alcohol pharmacokinetics and alcohol-drinking behavior in rats. Am J Clin Nutr 68:1512S-1515S.

Lovinger DM, Homanics GE (2007) Tonic for what ails us? High-affinity $\mathrm{GABA}_{\mathrm{A}}$ receptors and alcohol. Alcohol 41:139-143.

Lukas SE, Penetar D, Berko J, Vicens L, Palmer C, Mallya G, Macklin EA, Lee DY (2005) An extract of the Chinese herbal root kudzu reduces alcohol drinking by heavy drinkers in a naturalistic setting. Alcohol Clin Exp Res 29:756-762.

Mangan PS, Sun C, Carpenter M, Goodkin HP, Sieghart W, Kapur J (2005) Cultured hippocampal pyramidal neurons express two kinds of $\mathrm{GABA}_{\mathrm{A}}$ receptors. Mol Pharmacol 67:775-788.

Morrow AL, Montpied P, Lingford-Hughes A, Paul SM (1990) Chronic ethanol and pentobarbital administration in the rat: effects on $\mathrm{GABA}_{\mathrm{A}}$ receptor function and expression in brain. Alcohol 7:237-244.

Morrow AL, Biggio G, Serra M, Becker HC, Lopez MF, Porcu P, Alward SE, O'Buckley TK (2008) The role of neuroactive steroids in ethanol/stress interactions: proceedings of symposium VII at the Volterra conference on alcohol and stress. Alcohol 43:521-530.

Mukherjee S, Das SK, Vaidyanathan K, Vasudevan DM (2008) Consequences of alcohol consumption on neurotransmitters-an overview. Curr Neurovasc Res 5:266-272.

Olsen RW, Homanics GE (2000) Function of $\mathrm{GABA}_{\mathrm{A}}$ receptors: insights from mutant and knockout mice, in GABA in the nervous system: the view at fifty years (Martin DL, Olsen RW. eds), pp 81-96. Philadelphia: Lippincott Williams and Wilkins.

Olsen RW, Spigelman I (2012) $\mathrm{GABA}_{\mathrm{A}}$ receptor plasticity in alcohol withdrawal. In: Jasper's basic mechanisms of the epilepsies, Ed 4, Ch. 43 (Noebels JL, Avoli M, Rogawski MA, Olsen RW, Delgado-Escueta AV, eds). New York: Oxford UP, pp 562-573.

O’Malley SS, Rounsaville BJ, Farren C, Namkoong K, Wu R, Robinson J, O'Connor PG (2003) Initial and maintenance naltrexone treatment for alcohol dependence using primary care vs specialty care: a nested sequence of 3 randomized trials. Arch Intern Med 163:1695-1704.

Paul SM (2006) Alcohol-sensitive GABA receptors and alcohol antagonists. Proc Natl Acad Sci U S A 103:8307-8308.

Shen Y, Lindemeyer AK, Spigelman I, Sieghart W, Olsen RW, Liang J (2011) Plasticity of $\mathrm{GABA}_{\mathrm{A}}$ receptors following ethanol pre-exposure in cultured hippocampal neurons. Mol Pharmacol 79:432-442.

Siggins GR, Roberto M, Nie Z (2005) The tipsy terminal: presynaptic effects of ethanol. Pharmacol Ther 107:80-98.

Su J (659) The Tang Materia Medica.

Suzdak PD, Glowa JR, Crawley JN, Schwartz RD, Skolnick P, Paul SM (1986) A selective imidazobenzodiazepine antagonist of ethanol in the rat. Science 234:1243-1247.

Trevisan LA, Boutros N, Petrakis IL, Krystal JH (1998) Complications of alcohol withdrawal: pathophysiological insights. Alcohol Health Res World 22:61-66.

Valenzuela CF (1997) Alcohol and neurotransmitter interactions. Alcohol Health Res World 21:144-148.

Wallner M, Olsen RW (2008) Physiology and pharmacology of alcohol: the imidazobenzodiazepine alcohol antagonist site on subtypes of $\mathrm{GABA}_{\mathrm{A}} \mathrm{Rs}$ as an opportunity for drug 2012 development? Br J Pharmacol 154:288-298.

Wallner M, Hanchar HJ, Olsen RW (2003) Ethanol enhances $\alpha 4 \beta 3 \delta$ and $\alpha 6 \beta 3 \delta$ gamma-aminobutyric acid type A receptors at low concentrations known to affect humans. Proc Natl Acad Sci U S A 100:15218-15223.

Wallner M, Hanchar HJ, Olsen RW (2006) Low-dose alcohol actions on $\alpha 4 \beta 3 \delta \mathrm{GABA}_{\mathrm{A}}$ receptors are reversed by the behavioral alcohol antagonist Ro15-4513. Proc Natl Acad Sci U S A 103:8540-8545.

Wei W, Faria LC, Mody I (2004) Low ethanol concentrations selectively augment the tonic inhibition mediated by $\delta$ subunit-containing $\mathrm{GABA}_{\mathrm{A}}$ receptors in hippocampal neurons. J Neurosci 24:8379-8382.

Weiner JL, Valenzuela CF (2006) Ethanol modulation of GABAergic transmission: the view from the slice. Pharmacol Ther 111:533-554.

Youdim KA, Dobbie MS, Kuhnle G, Proteggente AR, Abbott NJ, Rice-Evans C (2003) Interaction between flavonoids and the blood-brain barrier: in vitro studies. J Neurochem 85:180-192. 